\title{
Changes in Anthropometric Parameters After Anti-TNFa Therapy in Inflammatory Bowel Disease: A Systematic Review and Meta-analysis
}

\author{
Faizan Mazhar ${ }^{1}$ - Vera Battini ${ }^{1}$ - Marco Pozzi ${ }^{2}$. Elena Invernizzi ${ }^{1}$. Giulia Mosini ${ }^{1}$. Michele Gringeri ${ }^{1}$. \\ Annalisa Capuano $^{3} \cdot$ Cristina Scavone $^{3} \cdot$ Sonia Radice ${ }^{1} \cdot$ Emilio Clementi $^{1,2} \cdot$ Carla Carnovale $^{1}$
}

Published online: 17 September 2020

(c) The Author(s) 2020

\begin{abstract}
Background Tumour necrosis factor (TNF)- $\alpha$ inhibitors have been widely used for the treatment of moderate-to-severe inflammatory bowel disease (IBD). TNF $\alpha$ also plays an important role in the regulation of weight homeostasis and metabolism and has been linked to variations in anthropometric responses. This relationship in patients with IBD has yet to be determined.

Objectives Our objective was to evaluate the effects of TNF $\alpha$ inhibitors on changes in anthropometric measures in both adults and children with IBD through a systematic review and meta-analysis.

Methods Multiple database searches identified studies involving children and adults with IBD and treated with TNF $\alpha$ inhibitors and reporting at least one primary outcome measure. Where possible, data were combined for meta-analysis. The primary outcomes included weight, body mass index (BMI), waist circumference, height, height/velocity, and fat and lean mass. Secondary outcomes included surrogate markers of disease activity. A random-effects model was used to estimate the standardised mean difference (SMD).

Results In total, 23 cohort studies (total 1167 participants) met the inclusion criteria. Meta-analysis was performed on 13 of these studies. In children, 6-29.3 months of anti-TNF $\alpha$ therapy had a small but statistically significant effect on weight (SMD 0.31; 95\% confidence interval [CI] 0.12-0.49; $P=0.001$ ) with a mean gain in $z$ score of 0.30 (standard error [SE] 0.12 ). In adults, 2-22.4 months of treatment had a moderate effect on BMI (SMD 0.72; 95\% CI 0.17-1.26; $P=0.010$; mean gain $1.23 \mathrm{~kg} / \mathrm{m}^{2}$; SE 0.21 ). A small but statistically significant increase in BMI $z$ score was found in children (SMD $0.28 ; 95 \%$ CI $0.03-0.53 ; P=0.026$; mean change $0.31 \pm$ standard deviation [SD] 0.14) after 12-29.3 months of therapy. A meta-analysis of four studies found a negligible but statistically significant increase in height (SMD 0.16; 95\% CI 0.06-0.26; $P=0.002$; mean change $0.17 z$ score [SE 0.05]). A negligible effect on fat mass (SMD 0.24; $95 \%$ CI $-0.19-0.66 ; P=0.272$ ) was found in a meta-analysis of five studies. Of note, despite the high heterogeneity among the studies that addressed the issue, these results were also consistently supported by findings from studies not included in the meta-analysis and reviewed in the systematic review. Unfortunately, a lack of data meant we were unable to perform moderator analysis on observed heterogeneity. Conclusion Anti-TNF $\alpha$ treatment appears to be associated with an increase in body weight, BMI, and other anthropometric parameters. Given the differing courses of IBD between children and adults, this association should be considered before initiating biologics for undernourished, overweight, and obese patients.
\end{abstract}

Registration: PROSPERO registration number CRD42020163079.

\section{Introduction}

Electronic supplementary material The online version of this article (https://doi.org/10.1007/s40259-020-00444-9) contains supplementary material, which is available to authorized users.

Sonia Radice

sonia.radice@unimi.it

Extended author information available on the last page of the article
Twenty years ago, infliximab was the first anti-tumour necrosis factor (TNF)- $\alpha$ monoclonal antibody approved for the treatment of moderate-to-severe inflammatory bowel disease (IBD) $[1,2]$. Elevated levels of TNF $\alpha$ are causally linked to muscle metabolism and provoke cachexia and sarcopenia $[3,4]$. TNF $\alpha$ is also a powerful regulator of lipid and glucose metabolism, exerting complex and diverse effects 


\section{Key Points}

Our analysis revealed a significant increase in the main anthropometric parameters (body weight, body mass index, and height) among patients with inflammatory bowel disease (IBD) treated with tumour necrosis factor (TNF) $-\alpha$ inhibitors.

Weight gain may be a risk factor for metabolic disorders and increases the likelihood of anti-TNF $\alpha$ therapy failure. The potential effect of TNF $\alpha$ inhibitors on anthropometric measures could be a consideration in the care of overweight and obese adults with IBD.

Weight loss is common during active IBD in children, and anti-TNF $\alpha$ agents could even exert positive improvements in weight and linear growth.

Further prospective studies are warranted to provide stronger evidence of the role of biological therapy on body changes, especially on fat and lean mass, in patients with IBD.

via gluconeogenesis, loss of adipose tissue, and proteolysis through regulation of enzymes involved in lipid metabolism, such as lipoprotein lipase, hormone-sensitive lipase, adipose triglyceride lipase, and acetyl-CoA carboxylase [5].

The inhibition of $\mathrm{TNF} \alpha$ and the subsequent reduction of the general inflammatory state may concurrently trigger adipogenesis, which in turn may improve constructive metabolism in muscles. Hence, the control of inflammation improves growth in children and leads to better general clinical conditions in adults.

Many studies have demonstrated statistically significant increases in body mass index (BMI) and/or body weight after anti-TNF $\alpha$ treatment in IBD $[1,2,6]$. Evaluating the impact of anti-TNF $\alpha$ therapy on anthropometric parameter changes in patients with IBD is of particular importance as the increase in lean mass is beneficial (muscle representing the protein reserves of the body and contributing to improved immune function). This is especially true in patients with aggressive IBD in which lower BMI values may result from malnutrition accompanied with severe inflammation [7]. Nevertheless, about $15-40 \%$ of patients with IBD are obese, and an additional $20-40 \%$ are overweight [9-13], so the potential involvement of adipose tissue in intestinal inflammation and therapeutic outcomes has gained increasing attention [10]. The increase in fat mass can also have significant implications in terms of augmented risk of obesity-related chronic diseases and suboptimal responses to therapy [8]. Pharmacokinetic studies have identified high body weight as a risk factor for suboptimal response, with the odds of a good response and achieving remission being lower in obese patients with IBD treated with anti-TNF $\alpha$ agents. High body weight is thought to be associated with increased clearance, shorter half-life, and lower serum trough drug concentrations of anti-TNF $\alpha$ agents [14-16].

The relationship between anti-TNF $\alpha$ therapy and changes in anthropometric indices in patients with IBD has not yet been determined. To address this, we performed a systematic review and meta-analysis of studies of anti-TNF $\alpha$ in adult and paediatric patients with IBD that reported changes in anthropometric parameters. We also analysed other clinical outcomes pertinent to the pathophysiology of IBD, such as measurements of body composition and biochemical parameters correlating with disease activity indices.

\section{Materials and Methods}

\subsection{Literature Search}

We followed the Preferred Reporting Items for Systematic Reviews and Meta-Analysis (PRISMA) guidelines (Table S1 in the electronic supplementary material [ESM]). We submitted our protocol to the International Prospective Register of Ongoing Systematic Reviews (ID: CRD42020163079) [17]. We searched PubMed/MEDLINE, Embase, and the Cochrane database up to 30 September 2019 with no language restriction. Our search strategy for PubMed is described fully in ESM 1 and was adapted as necessary for each database. In brief, we used the following three terms combined with the Boolean operator "AND": TNF $\alpha$ inhibitors, anthropometric parameters, and inflammatory bowel diseases.

\subsection{Eligibility Criteria}

Inclusion criteria were as follows: any study that assessed at least one anthropometric parameter following anti-TNF $\alpha$ therapy in patients with IBD and reported changes in those measures either for at least two time points (baseline and follow-up) or stratified results by anthropometric cut-off values. Conference proceedings/abstracts with relevant information on body changes were also included.

Studies were excluded if they (1) did not report values for baseline and follow-up, (2) reported the effect of anthropometric measures (e.g. BMI or weight) on treatment outcome rather than vice versa, or (3) included patients treated with parenteral or enteral nutrition or who received pharmacological treatment aimed to treat or prevent metabolic disorders. Case reports, case series, review articles, meta-analysis, 
book chapters, and unpublished thesis were not included. Studies in pregnant women were also excluded.

Additional articles were identified through the reference lists of articles included in our systematic review. We did not contact authors for unpublished data.

\subsection{Study Selection}

The titles and abstracts of retrieved references were imported into EndNote and duplicates eliminated. The titles and abstracts were screened, and papers deemed highly unlikely to be relevant were disregarded. Full-text versions of the remaining articles were obtained and assessed for eligibility based on our prespecified eligibility criteria as described in Sect. 2.2. The entire search process was conducted independently by two reviewers (VB and EI), and discrepancies were resolved by discussion with a third review author (FM) to reach a decision.

Two authors (VB and EI) assessed the risk of bias of studies included in the systematic review using the Newcastle-Ottawa Scale (NOS) [18]. The NOS is divided into three domains evaluating group selection, comparability of the cohort, and ascertainment of the outcome of interest. The scoring sheet allowed a maximum total score of 9 points (highest quality level). Disagreement was resolved by consensus and consultation with the expert group (CC and FM).

\subsection{Outcome Measures}

Primary outcomes were changes (from baseline) in the following anthropometric measures: weight $(\mathrm{kg}), \mathrm{BMI}\left(\mathrm{kg} / \mathrm{m}^{2}\right)$, waist circumference $(\mathrm{WC} ; \mathrm{cm})$, height $(\mathrm{cm})$, height/velocity ( $\mathrm{cm} /$ years), fat mass (bioelectrical impedance analysis [BIA]; \%), and lean mass (dual-energy X-ray absorptiometry [DXA]; kg).

Secondary outcomes included surrogate markers of disease activity (C-reactive protein [CRP], $\mathrm{mg} / \mathrm{dL}$ ), erythrocyte sedimentation rate $(\mathrm{ESR}, \mathrm{mm} / \mathrm{h})$, phase angle (PA, degrees $\left.{ }^{\circ}\right)$, and disease severity index scores, e.g. the Crohn's Disease Activity Index (CDAI) and the Mayo score.

\subsection{Data Extraction and Synthesis}

Extracted data from all included studies were compiled into an electronic summary table. The following pertinent information was extracted: change-from-baseline outcomes i.e. weight, BMI, WC, and other anthropometric measures. For paediatric patients, values for weight, BMI, and height were mostly reported as $z$ scores because of their growth variability. Information on the surrogate markers and disease severity index scores was also collected. Further parameters of interest, such as study type (blinding/design), study duration, number of subjects, number of patients naïve to biological treatment, sex distribution, age, medication type, dose, and concomitant treatment, were also included.

\subsection{Statistical Analysis}

All statistical analysis was conducted in ProMeta 3 software. For each outcome, change between baseline and follow-up after treatment commencement with a TNF $\alpha$ inhibitor was analysed. Where possible, the effect of anti-TNF $\alpha$ treatment on each different anthropometric measure was assessed in a separate meta-analysis. We considered the mean difference (MD) and their corresponding standard deviations (SDs) if reported in the primary study. If values were available as medians, they were converted to mean \pm SD provided they followed a normal distribution. For the missing correlations between baseline and follow-up, a correlation coefficient of 0.7 was imputed, as recommended by Rosenthal [19]. Studies with insufficient information to compute MD were excluded from the meta-analysis, and the main findings of individual studies were summarized separately. Standardised MDs (SMDs) were based on Cohen's $d$ with corresponding 95\% confidence interval (CIs) and were considered small $(d=0.2)$, medium $(d=0.5)$, and large $(d \geq 0.8)$ as per Cohen's classification scheme [20]. A $P$ value $<0.05$ was considered statistically significant. A random-effects model was used to account for both within-group variability and between-study heterogeneity. The between-study heterogeneity index was $I^{2}$. Results were considered heterogeneous when homogeneity was unlikely $(P<0.10)$. Forest plots were produced as a means of visualization. Possible publication bias was identified via visual assessment of a funnel plot.

For body weight, BMI, height, and fat mass, the SMD represents the effect estimate between baseline and followup. A positive effect estimate indicates that indice(s) was greater after treatment commencement, and a negative effect estimate indicates that indice(s) was lower after TNF $\alpha$ inhibitor commencement.

\section{Results}

\subsection{Study Characteristics}

The study selection and screening process is presented in the PRISMA flowchart (Fig. 1). Of the 1016 articles retrieved (340 results were from PubMed, 117 from Cochrane, and 559 from Embase), 23 met the inclusion criteria. Only 13 of the 23 included studies reported pre- and post-treatment changes in anthropometric measures and provided sufficient data to determine effect estimate.

Table 1 summarizes the characteristics of the studies evaluated in the systematic review and meta-analyses. Of the 23 
studies, 21 were observational (6 retrospective, 15 prospective) and two were open-label single-arm trials (yielding a total of 1167 patients aged between 1 month and 85 years).

The average age of patients in paediatric studies $(n=658)$ was 13-20 years (range 1 month-20 years). For adults $(n=509)$, the average age was $32-45$ years (range 18-85). Of the 1167 patients, 1053 (90.2\%) had Crohn's disease (CD); 96 (8.1\%) had ulcerative colitis (UC), two (0.16\%) had unclassified IBD, and four $(0.33 \%)$ had indeterminate colitis. With respect to the type of medication used, 22 studies reported data on infliximab $(n=989$ [84.7\%]), seven on adalimumab $(n=159[13.6 \%])$, and three on certolizumab pegol $(n=19[1.6 \%])$. As concomitant therapy, 79 (6.68\%) patients received corticosteroids, $188(16.1 \%)$ received aminosalicylates or nonsteroidal anti-inflammatory drugs, 453 (38.8\%) received immunomodulators, and four $(0.33 \%)$ received antibiotics. Eight studies enrolled paediatric patients (aged $<18$ years). The mean percentage of male patients was $51.27 \%$. The period from baseline to the last follow-up varied considerably among the studies, with a mean follow-up period of 15 months (range 1-29.3).

The quality of the included studies was moderate (mean NOS 5.5 \pm SD 0.51; Table S2 in the ESM). All the studies

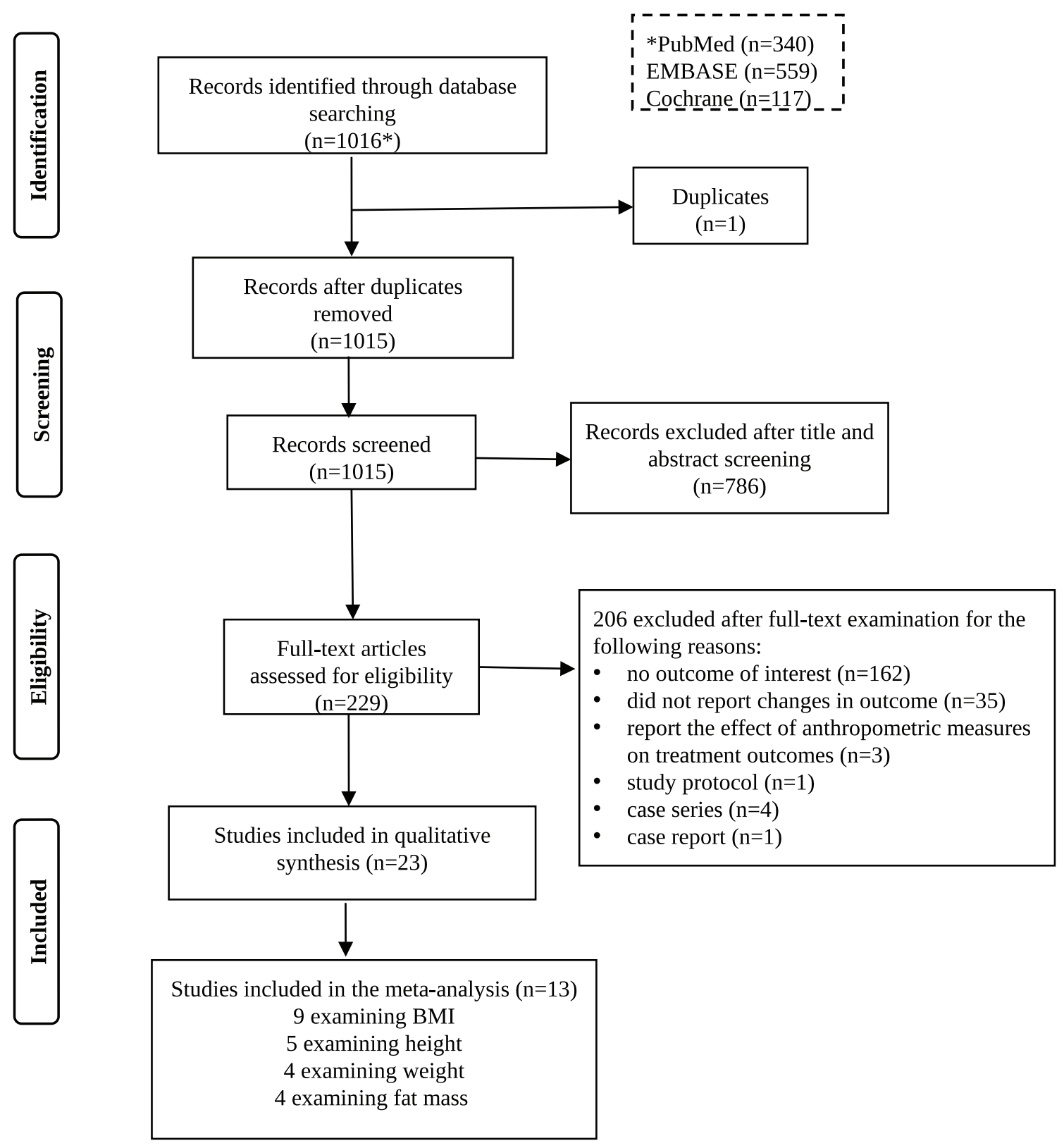

Fig. 1 PRISMA (Preferred Reporting Items for Systematic Reviews and Meta-analysis) flow diagram of process of study selection 


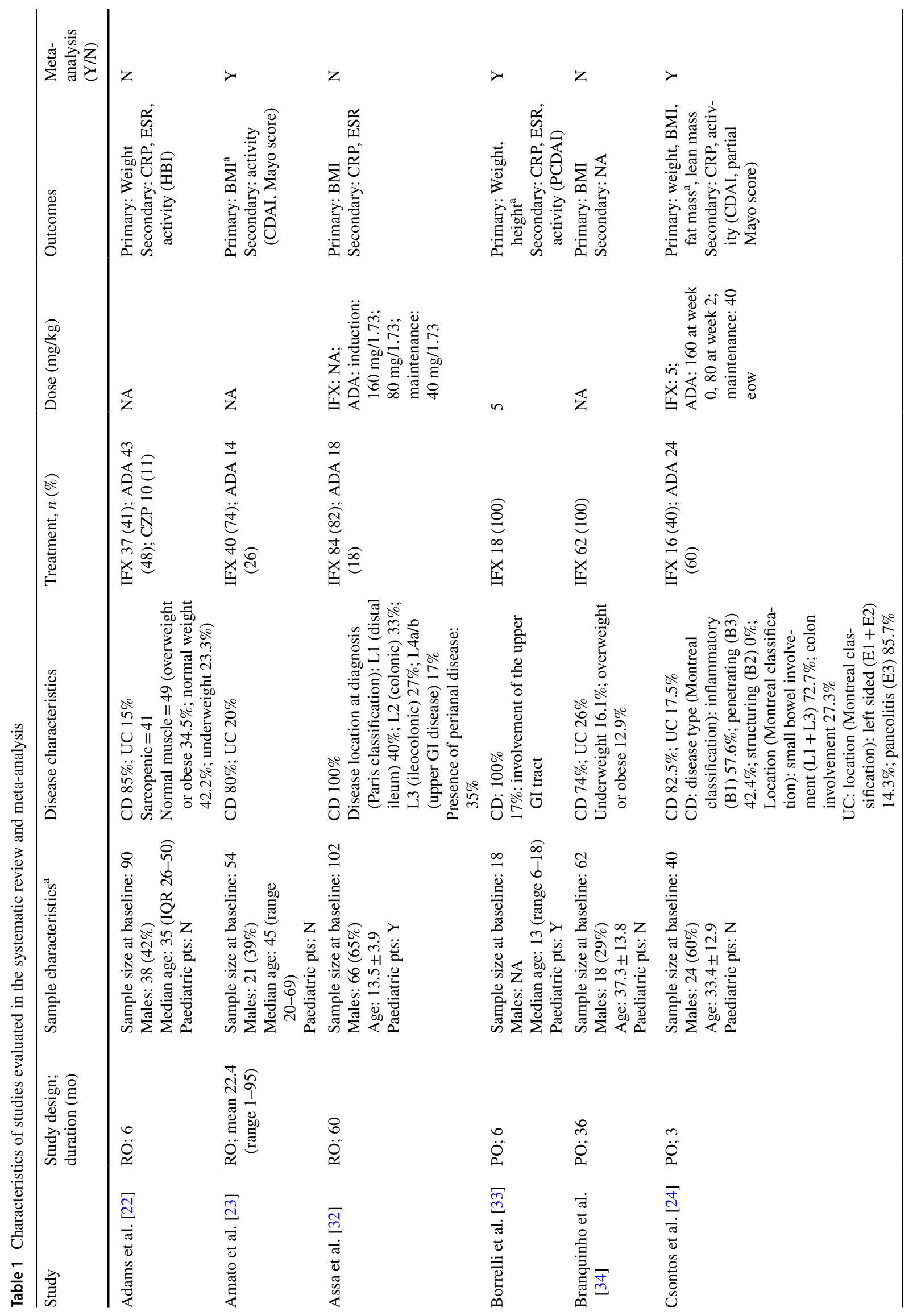




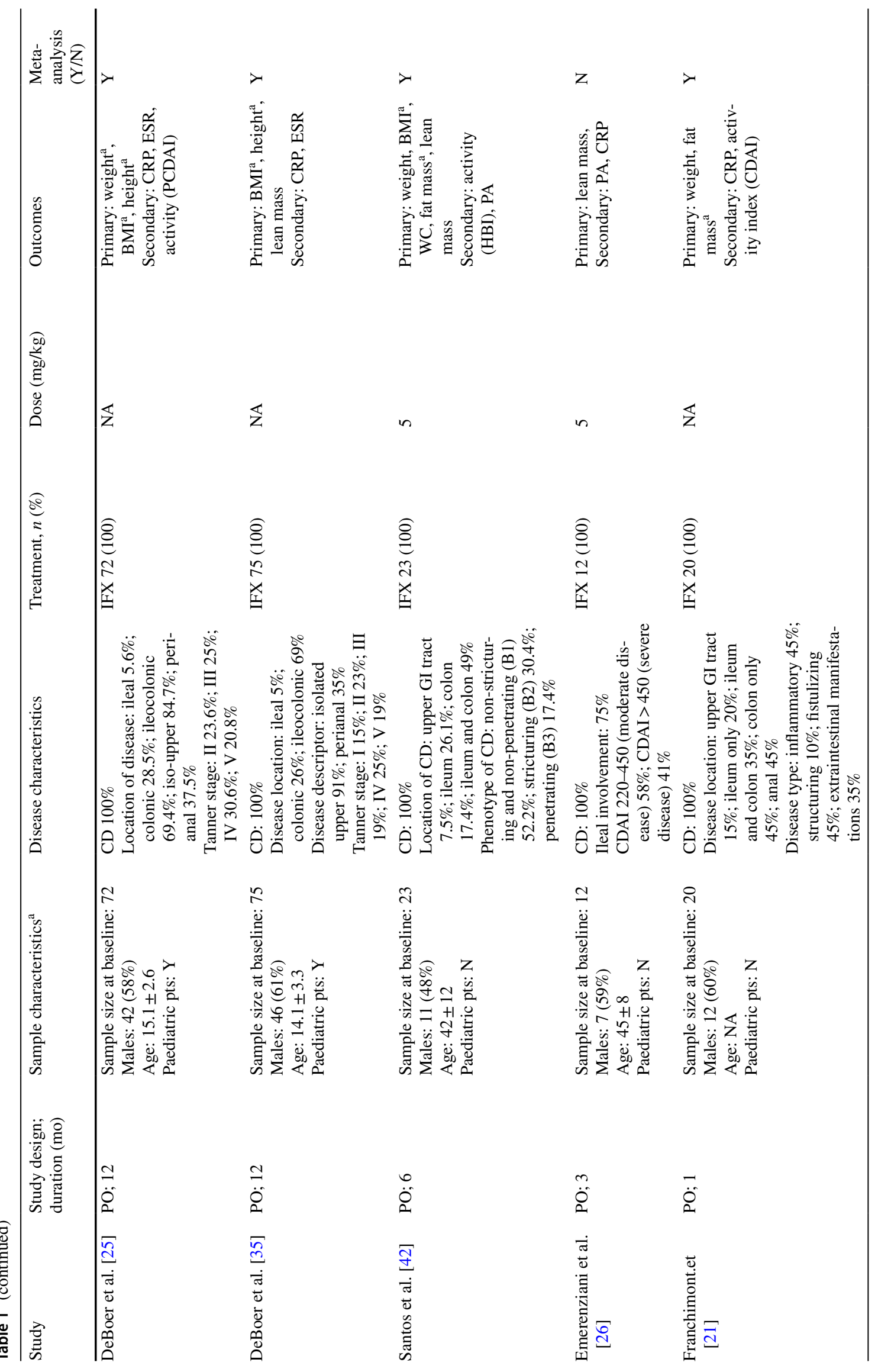




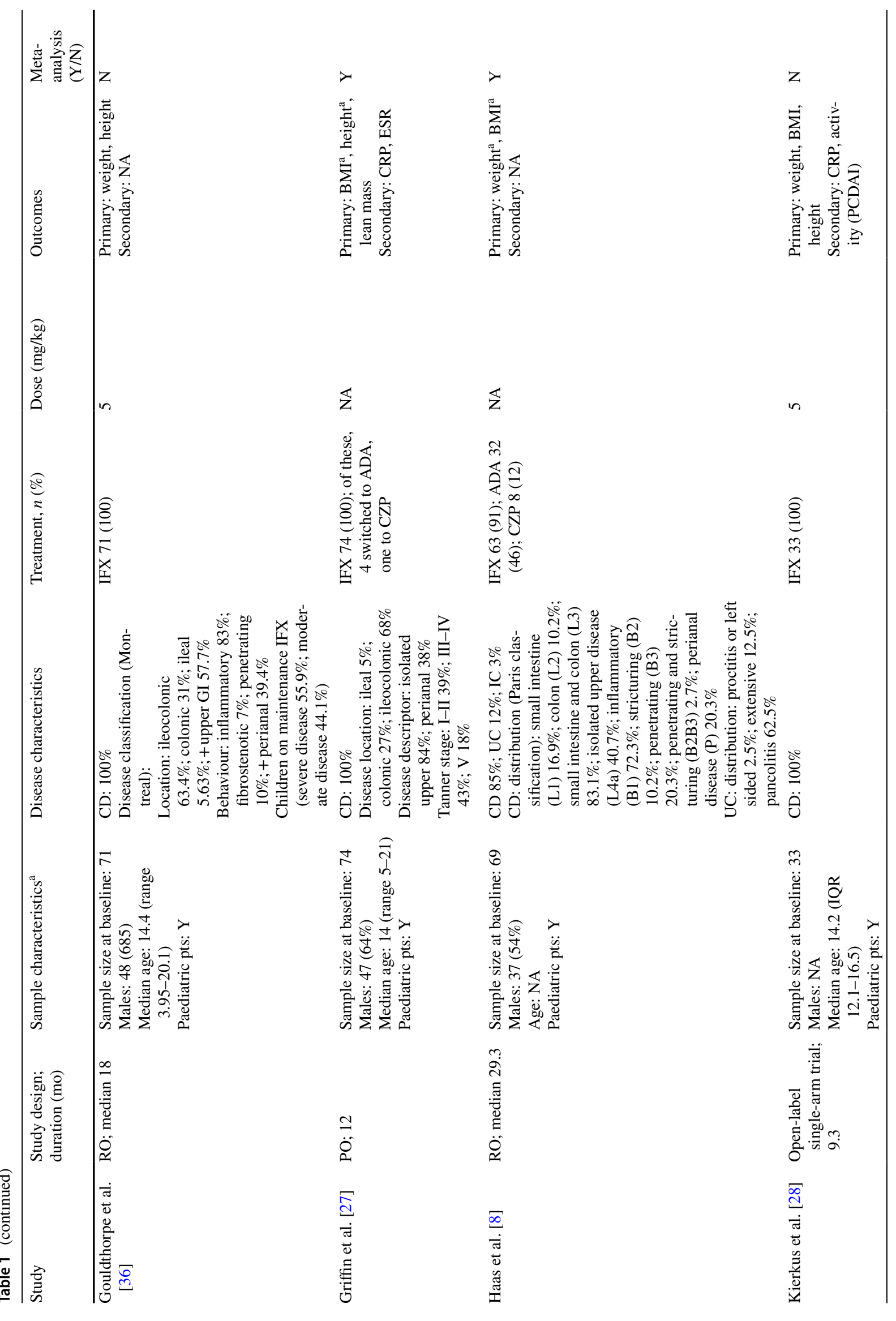




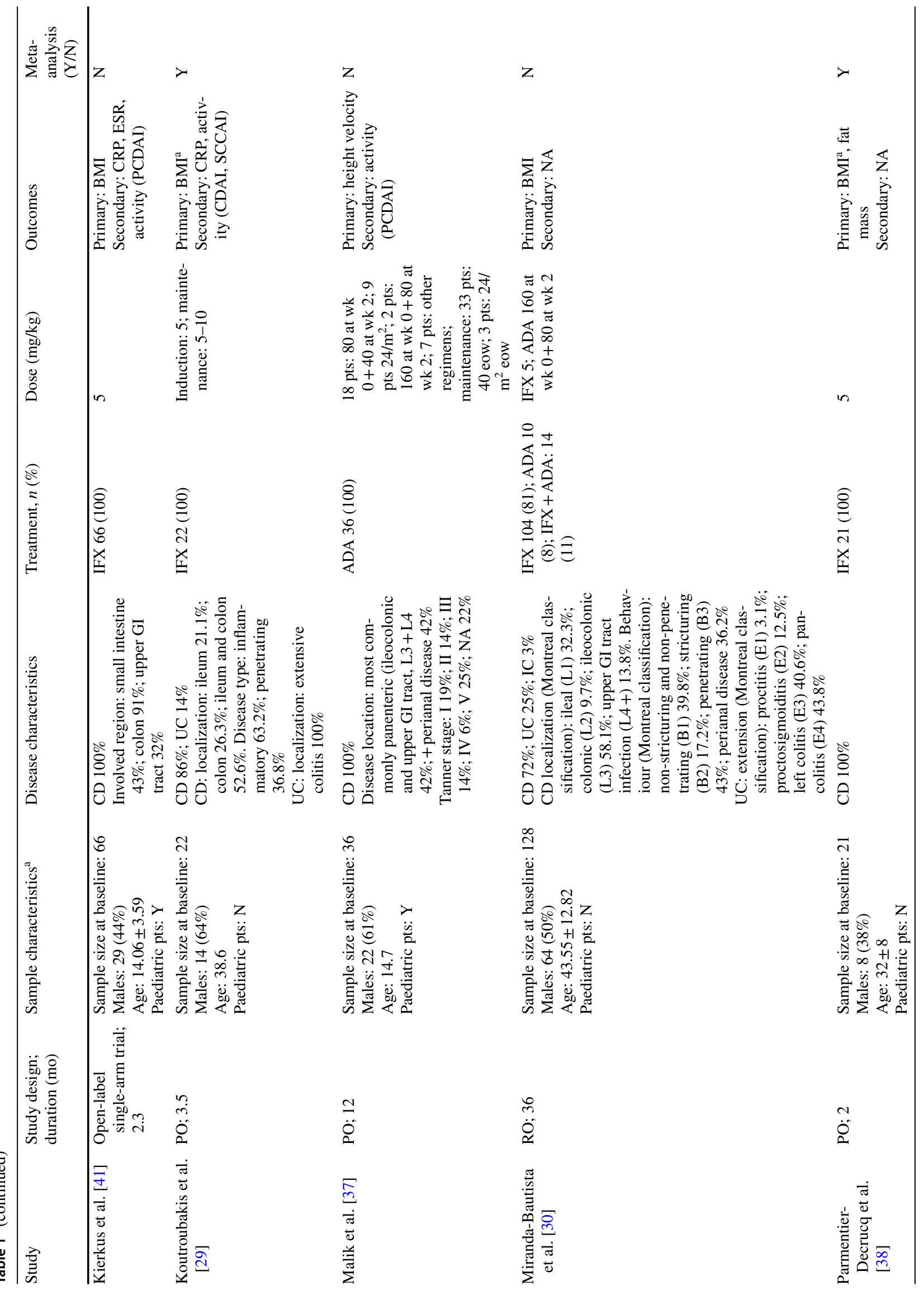




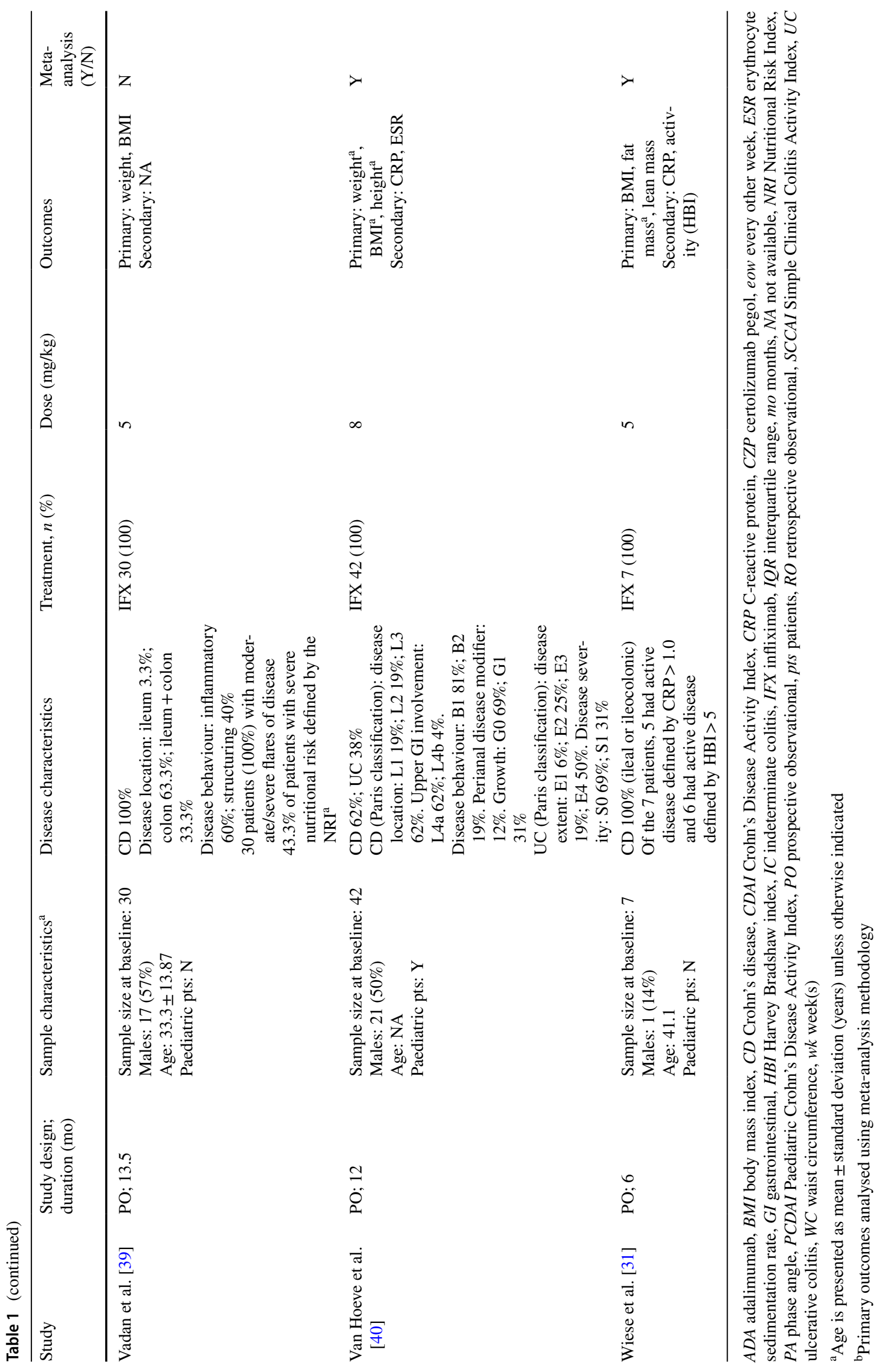


included in the review were rated as of moderate quality (NOS score 5-6). The most common quality issue was in the comparability domain.

\subsection{Primary Outcomes}

\subsubsection{The Effect of Tumour Necrosis Factor (TNF)- $a$ Inhibitors on Body Weight}

Of the 23 studies, 11 reported information on body weight changes. Of these, six involved paediatric patients (164 participants) $[8,25,33,35,36,40]$ and five involved adults [21, 22, 24, 39, 42]. For paediatrics, SMD calculation was possible for four of the six studies; these four studies were included in the meta-analysis $[8,25,33,40]$. The analysis revealed that patients' weight was significantly increased in children (SMD 0.31; 95\% CI 0.12-0.49; $P=0.001$ ) after the commencement of anti-TNF $\alpha$ therapy (duration range 6-29.3 months). Figure 2 illustrates the effects of antiTNF $\alpha$ pre- and post-treatment on weight in paediatrics. The weighted pooled mean increase in weight $z$ score was 0.30 (standard error [SE] 0.12). The between-study heterogeneity was significant $\left(P=0.096 ; I^{2}=52.74 \%\right)$. A funnel plot (Fig. 1a in the ESM) showed no potential publication bias. The remaining two studies that were excluded from analysis supported these findings (Table 2). Briefly, in one study, children with CD following maintenance therapy of infliximab significantly increased weight $z$ score by 0.51 $(P<0.001)$ [36]. Similarly, Kierkus et al. [28] reported a significant increase in body weight of $5.6 \mathrm{~kg}$ after 50 weeks of treatment.

We were unable to calculate SMDs for the adult populations, because of insufficient information: values for change in body weight for at least two time points were not reported. Although there was marked heterogeneity in the way in which the studies included patients with physical frailty, all the studies nevertheless reported a significant increase in body weight following anti-TNF $\alpha$ treatment (Table 2). Adams et al. [22] found a trend toward statistical difference for body weight change among patients with normal muscle mass $(\Delta 1.86 \mathrm{~kg}, \mathrm{P}=0.07)$ but not in those with sarcopenia $(\Delta 1.14 \mathrm{~kg}, P=0.4)$ after 6 months of anti-TNF $\alpha$ therapy. Vadan et al. [39] reported that undernourished patients had a significantly higher increase in body weight than wellnourished patients at the 30th and 54th week after anti-TNF $\alpha$ treatment. A significant increase in body weight was also found in the other three prospective studies after a mean duration of treatment of 3.33 months (range 1-6) [21, 24, 42].

\subsubsection{The Impact of TNFa Inhibitors on Body Mass Index} (BMI)

In total, 19 studies examined the effect of anti-TNF $\alpha$ on BMI. Of these, nine were eligible for meta-analysis. For paediatrics, the analysis of five studies (281 participants) $[8,25,27,35,40]$ revealed a significant effect of anti-TNF $\alpha$ on BMI (SMD 0.28; 95\% CI 0.03-0.53; $P=0.026$ ), with a weighted pooled mean change in BMI $z$ score of $0.31 \pm 0.14$ (Fig. 3a). The duration of anti-TNF $\alpha$ therapy ranged from 12 to 29.3 months (mean 15.46). Significant between-study heterogeneity was detected $\left(I^{2}=85.04 ; P<0.001\right)$. Funnel plots showed potential publication bias (Fig. $1 \mathrm{~b}$ in the ESM).

For adults, four studies with 120 participants were included in the meta-analysis [23, 29, 38, 42]. The duration of anti-TNF $\alpha$ therapy in included studies ranged from 2 to 22.4 months (mean 8.47). The overall effect was nonsignificant (SMD 0.72; 95\% CI 0.17-1.26; $P=0.1$ ), with an average BMI gain of $1.23 \mathrm{~kg} / \mathrm{m}^{2}$ (SE 0.21) (Fig. 3b). Statistically significant between-study heterogeneity was observed $\left(I^{2}=90.56 ; P<0.001\right)$. Funnel plots indicate potential publication bias (Fig. 1c in the ESM). We explored sources of heterogeneity using stratification and repeated the analysis using a random-effects model as an additional sensitivity analysis. A sensitivity analysis was conducted by excluding the conference abstract [23]. The gain in BMI remained significant (SMD 0.93; 95\% CI 0.42-1.43; $P<0.0001$ ) with considerable unexplained heterogeneity $\left(I^{2}=79.53\right.$; $P=0.008)$.

Table 2 summarizes the main findings for the remaining ten studies not included in the meta-analysis. Concerning children, in the study by Assa et al. [32], the clinical response was associated with an improvement in BMI $z$ scores $(-0.8$ to $-0.4 ; P=0.04)$. Likewise, Kierkus et al. $[28,41]$ reported a significant increase in BMI in children with severe $\mathrm{CD}$ treated with infliximab. For adults, Csontos et al. [24] reported significant BMI gain (from 23.81 \pm 7.19 at baseline to $24.52 \pm 7.34 \mathrm{~kg} / \mathrm{m}^{2}$ after 3 months; $P<0.001$ ). In a retrospective cohort of 128 patients who received at least three doses of infliximab or two doses of adalimumab, a significant increase in mean BMI was observed $(0.74$ and $1.44 \mathrm{~kg} / \mathrm{m}^{2}$ at 1 - and 3-year follow-up, respectively) [30]. Vadan et al. [39] evaluated 30 patients with CD undergoing infliximab therapy and observed a significant increase in BMI among underweight subjects (from 17.31 \pm 1.2 to $21.46 \pm 1.61 \mathrm{~kg} / \mathrm{m}^{2}$ ) and normal-weight subjects (from $23.24 \pm 2.27$ to $23.51 \pm 2.22 \mathrm{~kg} / \mathrm{m}^{2}$ ) after 54 weeks of treatment. In the study by Wiese et al. [31], seven patients experienced a gain in BMI of $2.21 \mathrm{~kg} / \mathrm{m}^{2}(P=0.03)$ after 6 months of infliximab treatment. Branquinho et al. [34] reported no significant change in BMI after induction treatment with infliximab, whilst an increase was noted at the 1-year follow-up (from 21.4 to $22.7 \mathrm{~kg} / \mathrm{m}^{2} ; P=0.049$ ), which became 
statistically significant after 3 years of therapy (from 21.4 to $\left.22.8 \mathrm{~kg} / \mathrm{m}^{2} ; P=0.026\right)$.

\subsubsection{The Impact of TNFa Inhibitors on Height}

For children, eight studies reported data on changes in height. Five of these, with 269 patients, were included in the meta-analysis (Fig. 4) [25, 27, 33, 35, 40]. The overall effect was significant (SMD 0.16; 95\% CI 0.06-0.26; $P=0.002)$. The weighted pooled mean increase in height $z$ score was 0.17 (SE 0.05). The between-study heterogeneity was nonsignificant $\left(I^{2}=11.19 ; P=0.342\right)$. The funnel plot showed no significant publication bias (Fig. 1d in the ESM). Findings from other paediatric studies not included in the meta-analysis confirmed a considerable increase in height after a treatment duration ranging from 9.3 to 18 months (Table 2) [28, 36, 37].

\subsubsection{The Impact of TNFa Inhibitors on Fat Mass}

Five studies reported changes in fat mass in adults [21, 24, $31,38,42]$; of these, four were eligible for inclusion in the meta-analysis (Fig. 5). We found an overall increase in fat mass (\%) (SMD 0.24; 95\% CI -0.19 to $0.66 ; P=0.272$ ), with considerable heterogeneity $\left(I^{2}=81.97 ; P=0.001\right)$. The funnel plot indicated a risk of publication bias (Fig. 1e in the ESM).

Other related reported outcomes were the body fat mass index (BFMI; $\left.\mathrm{kg} / \mathrm{m}^{2}\right)$, the visceral fat area $\left(\mathrm{cm}^{2}\right)$, and the total abdominal fat $\left(\mathrm{cm}^{3}\right)$; however, findings among studies were not consistent (Table 2). Parmentier et al. [38] reported a significant increase in total abdominal fat $(212 \pm 47$ vs. $\left.251 \pm 50 \mathrm{~cm}^{3} ; P=0.027\right)$ after 8 weeks of induction treatment with infliximab, whereas Csontos et al. [24] found that fat parameters had not changed significantly at week 12 (visceral fat area 95.65 vs. $85.00 \mathrm{~cm}^{2} ; P=0.730$; BFMI: 4.57 vs. $4.76 \mathrm{~kg} / \mathrm{m}^{2} ; P=0.120$ ). Santos et al. [42] reported a significant increase in fat mass index (fat mass $[\mathrm{kg}] / \mathrm{squared}$ height: $5.5 \pm 2.3$ vs. $6.8 \pm 2.3 ; P=0.000$ ).

\subsubsection{The Impact of TNFa Inhibitors on Lean Mass}

Six studies, with 231 patients, examined the effect of anti$\mathrm{TNF} \alpha$ treatment on lean mass [24, 26, 27, 31, 35, 42]. Information was insufficient to compute the SMD, and the main findings of individual studies are summarised here.

Data on changes in lean mass were available in six paediatric studies ( $\mathrm{n}=231$ patients) $[24,26,27,31,35,42]$ not eligible for inclusion in the meta-analysis. Briefly, the period of observation ranged from 3 to 12 months. Csontos et al. [24] found a significant increase in skeletal mass index $(P=0.003)$ and fat-free mass index (FFMI) at week $12(P<0.00)$, along with a significant increase in food intake. Similarly, a significant increase in lean mass index (LMI) was also reported by Santos et al. [42] (17.5 \pm 2.2 vs. $\left.18.1 \pm 2.3 \mathrm{~kg} / \mathrm{m}^{2} ; P<0.001\right)$. Emerenziani et al. [26] reported a nonsignificant increase in FFMI among patients started on infliximab compared with patients on conventional treatment $(41.7 \pm 3.7$ vs. $44.6 \pm 4.2 \mathrm{~kg} ; P<0.05)$. Similarly, Griffin et al. [27] reported that Paediatric Crohn's Disease Activity Index (PCDAI) scores decreased after 10-week induction treatment, with subsequent gains in muscle area after 12 months $(z$ scores $-0.81 \pm 1.10$ vs. $-0.35 \pm 1.10$; $P<0.01)$.

All studies observed lean body mass (LBM) values after anti-TNF $\alpha$ therapy in a period of observation ranging from 3 to 12 months. In brief, Csontos et al. [24] found a significant increase in both food intake and skeletal mass index $(P=0.003)$ and the FFMI $(P<0.00)$ in patients with IBD at week 12. Similarly, a significant increase in LMI was also reported by Santos et al. [42] $(17.5 \pm 2.2$ vs. $18.1 \pm 2.3 \mathrm{~kg} /$ $\left.\mathrm{m}^{2} ; P<0.001\right)$. Emerenziani et al. [26] reported a nonsignificant increase in FFMI in patients on infliximab therapy compared with patients on conventional therapy $(41.7 \pm 3.7$ vs. $44.6 \pm 4.2 \mathrm{~kg} ; P<0.05)$. Similarly, Griffin et al. [27] reported that PCDAI scores decreased during the 10-week induction, with subsequent gains in muscle area $z$ scores after 12 months $\left(-0.81 \pm 1.10\right.$ vs. $\left.-0.35 \pm 1.10 \mathrm{~mm}^{2} ; P<0.01\right)$. In a prospective cohort study of 75 patients aged 5-21 years with $\mathrm{CD}$, leg lean mass score increased significantly following 12 months of anti-TNF $\alpha$ therapy $(-0.76 \pm 1.04$ vs. $-0.27 \pm 1.01 \mathrm{~kg} ; P<0.001)$ [35]. In contrast, no significant change in the LBM per DXA value was observed by Wiese et al. [31] (from 39.16 at baseline to $40.03 \mathrm{~kg} ; \Delta 0.87 \mathrm{~kg}$; $P=0.44$ ) after 6 months of infliximab treatment in seven patients with $\mathrm{CD}$.

\subsubsection{The Impact of TNFa Inhibitors on Waist Circumference}

Only one study examined change in WC after commencement of anti-TNF $\alpha$ therapy [42]. A significant increase in WC (from $88.1 \pm 6.7$ at baseline to $93.9 \pm 7.7 \mathrm{~cm} ; P<0.05$ ) was found in adults with moderate-to-severe $\mathrm{CD}$ after 6 months of anti-TNF $\alpha$ therapy.

\subsection{Secondary Outcomes}

In total, 21 studies reported secondary outcomes, i.e. laboratory markers of disease activity, disease severity index scores, and changes in PA (Table 3 in the ESM). In all studies, the efficacy of treatment in reducing disease activity was confirmed by a significant reduction in both surrogate markers of disease activity (i.e. ESR and CRP) and severity index scores, regardless of IBD type (CD or UC) and population (children or adults). A limited number of studies reported on the effect of anti-TNF $\alpha$ treatment on PA. 
Only two studies examined the influence of anti-TNF $\alpha$ treatment on PA in IBD, but the findings were conflicting. PA remained unchanged ( 6.2 vs. $6.8 ; P=0.94)$ in the study by Santos et al. [42], whereas Emerenziani et al. [26] found a significant increase in mean PA scores (from $4.6 \pm 0.3$ to $6.2 \pm 0.4 ; P<0.05)$ (Table 2 )

\section{Discussion}

Evidence addressing the relationship between anti-TNF $\alpha$ agents and variations in body composition is of primary importance in the assessment of safety and efficacy outcomes with this pharmacological approach. Previous studies revealed contradictory results concerning the effects of anti-TNF $\alpha$ therapy on body composition in rheumatological patients [44-46].

This is the first systematic review aimed at evaluating the impact of anti-TNF $\alpha$ therapy on anthropometric variations in adult and paediatric patients with IBD. In doing so, we took care to consider all aspects that were revealing of disease activity indices. The goal was to determine whether the weight gain was due to an increase in fat or muscle mass and to improve knowledge on any potential effect related to anti-TNF $\alpha$ therapy. To maximize comparability and minimize potential bias, we excluded studies with the possible confounding effect of parenteral or enteral nutrition or in patients receiving pharmacological treatment to control or prevent metabolic disorders.
We found evidence for a statistically significant impact of TNF $\alpha$ inhibitors on BMI in both adults (SMD 0.72; 95\% CI $0.17-1.26 ; P=0.010$ ) and children (SMD 0.28; $95 \%$ CI $0.03-0.53 ; P=0.026)$. The SMD was larger for adults than for children. Furthermore, there was a small but statistically significant effect on body weight (SMD 0.31; 95\% CI $0.12-0.49 ; P=0.001)$ and height (SMD $0.16 ; 95 \% \mathrm{CI}$ $0.06-0.26 ; P=0.002)$.

Relatedly, and of note, despite the high heterogeneity among studies that addressed the issue, these results were also consistently supported by findings from studies not included in the meta-analysis and reviewed in the systematic review. Unfortunately, because of the lack of data, we could not perform moderator analysis on observed heterogeneity. Such heterogeneity might be attributed to variations in study patients, sex, disease severity, type of anti-TNF $\alpha$, and concomitant treatment as well as the remitting and relapsing nature of IBD.

BMI and body weight changes were the main outcomes most commonly reported. There was a meaningful increase in BMI from baseline in all studies; this effect was more evident in studies dealing with long-term follow-up, especially after 3 years of therapy, showing an increase in BMI of $1.4 \mathrm{~kg} / \mathrm{m}^{2}[30,34]$. In line with this, we found an overall increase in BMI of $1.23 \pm 2.3 \mathrm{~kg} / \mathrm{m}^{2}$ from baseline after a therapy duration ranging from 2 to 22.4 months. Similarly, we noted an increase in weight in both adults and children after a mean duration of 6 and 12.4 months of treatment, respectively. In line with this, increased WC was evident after infliximab therapy $(88.1 \pm 6.7$ vs. $93.9 \pm 7.7 \mathrm{~cm}$; $P<0.05)$ in adults with moderate-to-severe CD [42].

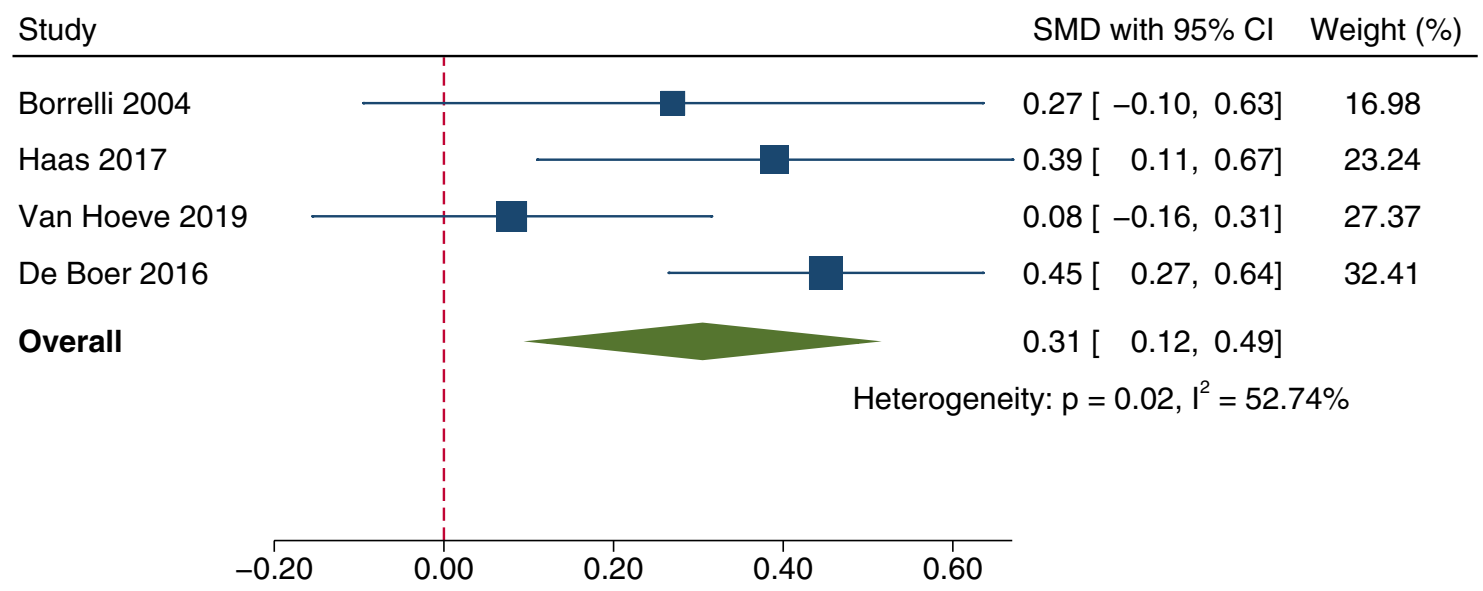

Random-effects REML model

Fig. 2 Forest plot showing the change in body weight between baseline and after treatment commencement with a tumour necrosis factor (TNF)- $\alpha$ inhibitor in paediatric patients. Standardized mean difference (SMD) estimates were based on Cohen's d with corresponding
95\% confidence intervals (CIs) and were considered small $(d=0.2)$, medium $(d=0.5)$, and large $(d \geq 0.8)$ as per Cohen's classification scheme [20]. A $P$ value $<0.05$ was considered statistically significant 
Table 2 Summary of post anti-tumour necrosis factor- $\alpha$ treatment changes in anthropometric measures in studies excluded from meta-analysis

\begin{tabular}{|c|c|c|c|c|c|}
\hline Outcome & Study & Baseline & Endpoint & Variation $^{\mathrm{a}}$ & $\begin{array}{l}\text { Duration of anti-TNF } \\
\text { therapy }\end{array}$ \\
\hline \multirow[t]{7}{*}{ Body weight (kg) } & Adams et al. [22] & NR & NR & $\begin{array}{l}\text { Entire cohort: } 1.5 \\
\quad(P=0.06) \\
\text { Sarcopenic: } 1.14 \\
\quad(P=0.4) \\
\text { Normal muscle: } 1.86 \\
\quad(P=0.07)\end{array}$ & $\begin{array}{l}6 \text { months (IFX, ADA, } \\
\text { CZP) }\end{array}$ \\
\hline & Csontos et al. [24] & $63.4(58.82-79.40)^{\mathrm{b}}$ & $63.7(58.49-82.65)^{\mathrm{b}}$ & $\begin{array}{l}\text { Overall: NR; Sig- } \\
\text { nificant increase } \\
(P<0.001) \\
\text { Stratified by disease } \\
\quad \text { severity: } \\
\text { Mild } 3.54 \pm 3.59 \\
\text { Moderate } 1.87 \pm 2.60 \\
\text { Severe } 0.98 \pm 2.67\end{array}$ & 3 months (IFX, ADA) \\
\hline & Santos et al. [42] & $62.6 \pm 9.5$ & $68.4 \pm 13.2$ & $\begin{array}{l}\text { NR; significant } \\
\text { increase }(P=0.006)\end{array}$ & 6 months (IFX) \\
\hline & $\begin{array}{l}\text { Franchimont et al. } \\
\text { [21] }\end{array}$ & $63.6(3.6)^{\mathrm{c}}$ & $64.4(3.5)^{\mathrm{c}}$ & $\begin{array}{l}\text { NR; significant } \\
\quad \text { increase }(P=0.013)\end{array}$ & 1 month (IFX) \\
\hline & $\begin{array}{l}\text { Gouldthorpe et al. } \\
\text { [36] }\end{array}$ & $\begin{array}{l}\text { Weight-for-age SDS: } \\
-0.77^{\mathrm{b}}\end{array}$ & $\begin{array}{l}\text { Weight-for-age SDS: } \\
+0.48^{\mathrm{b}}\end{array}$ & $\begin{array}{l}\text { NR; significant } \\
\text { increase }(P<0.05)\end{array}$ & 44 months (IFX) \\
\hline & Kierkus et al. [28] & $43(36.2-50.7)^{\mathrm{d}}$ & $48.6(42-53.5)^{\mathrm{d}}$ & NR & 10 months (IFX) \\
\hline & Vadan et al. [39] & NR & NR & $\begin{array}{l}\text { Stratified by BMI } \\
\text { category: } \\
\text { Baseline BMI }<18.5 \text { : } \\
11.2 \pm 3.58 \\
(P=0.002) \\
\text { Baseline BMI }>18.5: \\
6.58 \pm 2.32\end{array}$ & 13.5 months (IFX) \\
\hline \multirow[t]{8}{*}{ BMI $\left(\mathrm{kg} / \mathrm{m}^{2}\right)$} & Assa et al. [32] & $\begin{array}{l}\text { BMI for age and sex } \\
\text { SDS, } z \text { scores: }-0.8^{\mathrm{e}}\end{array}$ & $\begin{array}{l}\text { BMI for age and sex } \\
\text { SDS, } z \text { scores: }-0.4^{\mathrm{e}}\end{array}$ & $\begin{array}{l}\text { NR; significant } \\
\quad \text { increase }(P=0.04)\end{array}$ & 60 months (IFX, ADA) \\
\hline & Branquinho et al. [34] & $21.4 \pm 3.07$ & $22.8^{\mathrm{e}}$ & $\begin{array}{l}\text { NR; nonsignifi- } \\
\text { cant increase at } \\
1 \text { year, significant } \\
\text { increase at } 3 \text { years } \\
(P=0.026)\end{array}$ & 36 months (IFX) \\
\hline & Csontos et al. [24] & $21.75(19.20-26.55)^{\mathrm{b}}$ & $22.5(20.17-27.02)^{\mathrm{b}}$ & $\begin{array}{l}\text { Overall: NR; sig- } \\
\text { nificant increase } \\
(P<0.001) \\
\text { Stratified by disease } \\
\quad \text { severity } \\
\text { Mild } 1.16 \pm 1.19 \\
\text { Moderate } 0.63 \pm 0.88 \\
\text { Severe } 0.34 \pm 0.91\end{array}$ & 3 months (IFX, ADA) \\
\hline & Kierkus et al. [41] & $17.9(16.4-19.5)^{\mathrm{d}}$ & $18.9(16.9-20)^{\mathrm{d}}$ & $\begin{array}{l}\text { NR; significant } \\
\text { increase }\end{array}$ & 10 months (IFX) \\
\hline & Kierkus et al. [28] & $17.5(15.4-19.4)^{\mathrm{b}}$ & $18(16.7-20)^{\mathrm{b}}$ & $\begin{array}{l}\text { NR; significant } \\
\text { increase }\end{array}$ & 2.5 months (IFX) \\
\hline & $\begin{array}{l}\text { Miranda-Bautista } \\
\text { et al. [30] }\end{array}$ & $23.9 \pm 4.6$ & NR & $1.44 \pm 3.5(P<0.001)$ & 36 months (IFX, ADA) \\
\hline & Vadan et al. [39] & $\begin{array}{l}\text { Baseline } \mathrm{BMI}<18.5 \\
17.31 \pm 1.22 \\
\text { Baseline } \mathrm{BMI}>18.5 \\
21.03 \pm 2.1\end{array}$ & $\begin{array}{l}\text { Baseline } \mathrm{BMI}<18.5: \\
21.46 \pm 1.61 \\
\text { Baseline } \mathrm{BMI}>18.5 \\
23.51 \pm 2.22\end{array}$ & $\begin{array}{l}\text { NR; significant } \\
\quad \text { increase }(P=0.01)\end{array}$ & 13.5 months (IFX) \\
\hline & Wiese et al. [31] & $24.45^{\mathrm{e}}$ & $26.66^{\mathrm{e}}$ & $2.21(P=0.03)^{\mathrm{e}}$ & 6 months (IFX) \\
\hline
\end{tabular}


Table 2 (continued)

\begin{tabular}{|c|c|c|c|c|c|}
\hline Outcome & Study & Baseline & Endpoint & Variation $^{\mathrm{a}}$ & $\begin{array}{l}\text { Duration of anti-TNF } \\
\text { therapy }\end{array}$ \\
\hline \multirow[t]{2}{*}{ Height (cm) } & $\begin{array}{l}\text { Gouldthorpe et al. } \\
\text { [36] }\end{array}$ & $\begin{array}{l}\text { Height-for-age SDS: } \\
-0.33^{\mathrm{b}}\end{array}$ & $\begin{array}{l}\text { Height-for-age SDS: } \\
0.86^{\mathrm{b}}\end{array}$ & $\begin{array}{l}\text { NR; significant } \\
\text { increase }(P<0.05)\end{array}$ & 44 months (IFX) \\
\hline & Kierkus et al. [28] & $154.3(142-164.5)^{\mathrm{d}}$ & $158.5(152-168.5)^{\mathrm{d}}$ & $\begin{array}{l}\text { NR; significant } \\
\text { increase }\end{array}$ & 10 months (IFX) \\
\hline $\begin{array}{l}\text { Height velocity } \\
(\mathrm{cm} / \mathrm{y})\end{array}$ & Malik et al. [37] & $2(0-5.8)^{f}$ & $4.2(0-10.3)^{\mathrm{f}}$ & $\begin{array}{l}\text { NR; nonsignificant } \\
\text { increase }(P=0.11)\end{array}$ & 12 months (ADA) \\
\hline \multirow[t]{3}{*}{ Fat mass } & $\begin{array}{l}\text { Parmentier-Decrucq } \\
\text { et al. [38] }\end{array}$ & $\operatorname{TAF}\left(\mathrm{cm}^{3}\right): 212 \pm 47$ & $\operatorname{TAF}\left(\mathrm{cm}^{3}\right): 251 \pm 50$ & $\begin{array}{l}\text { NR; significant } \\
\text { increase }(P=0.027)\end{array}$ & 2 months (IFX) \\
\hline & Csontos et al. [24] & $\begin{array}{l}\text { Visceral fat area: } \\
95.65 \mathrm{~cm}^{3} \\
\text { BFMI: } 4.57 \mathrm{~kg} / \mathrm{m}^{2}\end{array}$ & $\begin{array}{l}\text { Visceral fat area: } \\
85.00 \mathrm{~cm}^{3} \\
\text { BFMI: } 4.76 \mathrm{~kg} / \mathrm{m}^{2}\end{array}$ & $\begin{array}{l}\text { NR; nonsignificant } \\
\text { increase }\end{array}$ & \\
\hline & Santos et al. [42] & BFMI: $5.5 \pm 2.3 \mathrm{~kg}$ & BFMI: $6.8 \pm 2.3 \mathrm{~kg}$ & $\begin{array}{l}\text { NR; significant } \\
\text { increase }\end{array}$ & \\
\hline \multirow[t]{6}{*}{ Lean mass } & Csontos et al. [24] & $\begin{array}{l}\text { FFMI: } 17.64 \pm 3 \\
\text { SMI }\left(\mathrm{kg} / \mathrm{m}^{2}\right): \\
9.81 \pm 1.83\end{array}$ & $\begin{array}{l}\text { FFMI: } 18.14 \pm 3.08 \\
\text { SMI: } 10.05 \pm 1.90\end{array}$ & $\begin{array}{l}\text { NR; significant } \\
\text { increase }(P<0.001) \\
\text { Stratified by disease } \\
\text { severity (FFMI): } \\
\text { Mild } 1.02 \pm 0.74 \\
\text { Moderate } 0.46 \pm 0.68 \\
\text { Severe }-0.05 \pm 0.61 \\
\text { Differences within } \\
\text { mild and severe } \\
\text { disease activity sub- } \\
\text { groups }(P=0.005)\end{array}$ & 3 months (IFX, ADA) \\
\hline & DeBoer et al. [25] & LegLM: $-0.76 \pm 1.04$ & LegLM: $-0.27 \pm 1.01$ & $\begin{array}{l}\text { NR; significant } \\
\text { increase }(P<0.001)\end{array}$ & 12 months (IFX) \\
\hline & Santos et al. [42] & LMI: $17.5 \pm 2.2$ & LMI: $18.1 \pm 2.3$ & $\begin{array}{l}\text { NR; significant } \\
\text { increase }(P=0.000)\end{array}$ & 6 months (IFX) \\
\hline & $\begin{array}{l}\text { Emerenziani et al. } \\
\text { [26] }\end{array}$ & FFM: $41.7 \pm 3.7$ & FFM: $44.6 \pm 4.2$ & $\begin{array}{l}\text { NR; significant } \\
\text { increase }\end{array}$ & 3 months (IFX) \\
\hline & Griffin et al. [27] & $\begin{array}{c}\text { Muscle CSA }\left(\mathrm{mm}^{2}\right), z \\
\text { score: }-0.81 \pm 1.10\end{array}$ & $\begin{array}{r}\text { Muscle CSA }\left(\mathrm{mm}^{2}\right), z \\
\text { score: }-0.35 \pm 1.06\end{array}$ & $\begin{array}{l}\text { Muscle CSA }\left(\mathrm{mm}^{2}\right) \text {, } \\
z \text { score: } 0.46 \pm 0.78 \\
(P<0.01)\end{array}$ & $\begin{array}{l}12 \text { months (IFX, ADA, } \\
\text { CZP) }\end{array}$ \\
\hline & Wiese et al. [31] & DXA (kg): $39.16^{\mathrm{e}}$ & DXA (kg): $40.03^{\mathrm{e}}$ & $\begin{array}{l}\text { DXA }(\mathrm{g}): 872.33 \\
\quad(P=0.4)^{\mathrm{e}}\end{array}$ & 6 months (IFX) \\
\hline $\mathrm{WC}(\mathrm{cm})$ & Santos et al. [42] & $88.1 \pm 6.7$ & $93.9 \pm 7.7$ & $\begin{array}{l}\text { NR; significant } \\
\text { increase }(P=0.002)\end{array}$ & 6 months (IFX) \\
\hline
\end{tabular}

Data are presented as mean \pm SD unless otherwise indicated

$\mathrm{NRI}=1.519 \times$ serum albumin $(\mathrm{g} / \mathrm{L})+41.7 \times($ current/usual body weight $)$

$A D A$ adalimumab, $B F M I$ body fat mass index, $B M I$ body mass index, CSA cross-sectional area, CZP certolizumab, DXA dual-energy X-ray absorptiometry, FFM fat-free mass, FFMI Fat-Free Mass Index, IFX infliximab, IQR interquartile range, LegLM leg lean mass, $L M I$ lean mass index, $N R$ not reported, NRI Nutritional Risk Index, SD standard deviation, SDS standard deviation scores, SEM standard error of the mean, SMI Skeletal Muscle Mass Index, $T A F$ total abdominal fat, $T N F$ tumour necrosis factor, $W C$ waist circumference

${ }^{a}$ Presented as change $(\Delta)$ unless otherwise specified

${ }^{\mathrm{b}}$ Median (IQR)

${ }^{\mathrm{c}}$ Mean (SEM)

${ }^{\mathrm{d}}$ Median (range)

${ }^{\mathrm{e}} \mathrm{Mean} \pm \mathrm{SD}$

${ }^{\mathrm{f}}$ Median (10th-90th centiles)

Importantly, responders had significant improvements in body weight and BMI compared with nonresponders, which may reflect early discontinuation of treatment in nonresponders and a switch to an alternative treatment. Factors such as age, disease duration, smoking, or other medication did not appear to have a significant association with BMI, suggesting that anti-TNF $\alpha$ therapy may play a significant 


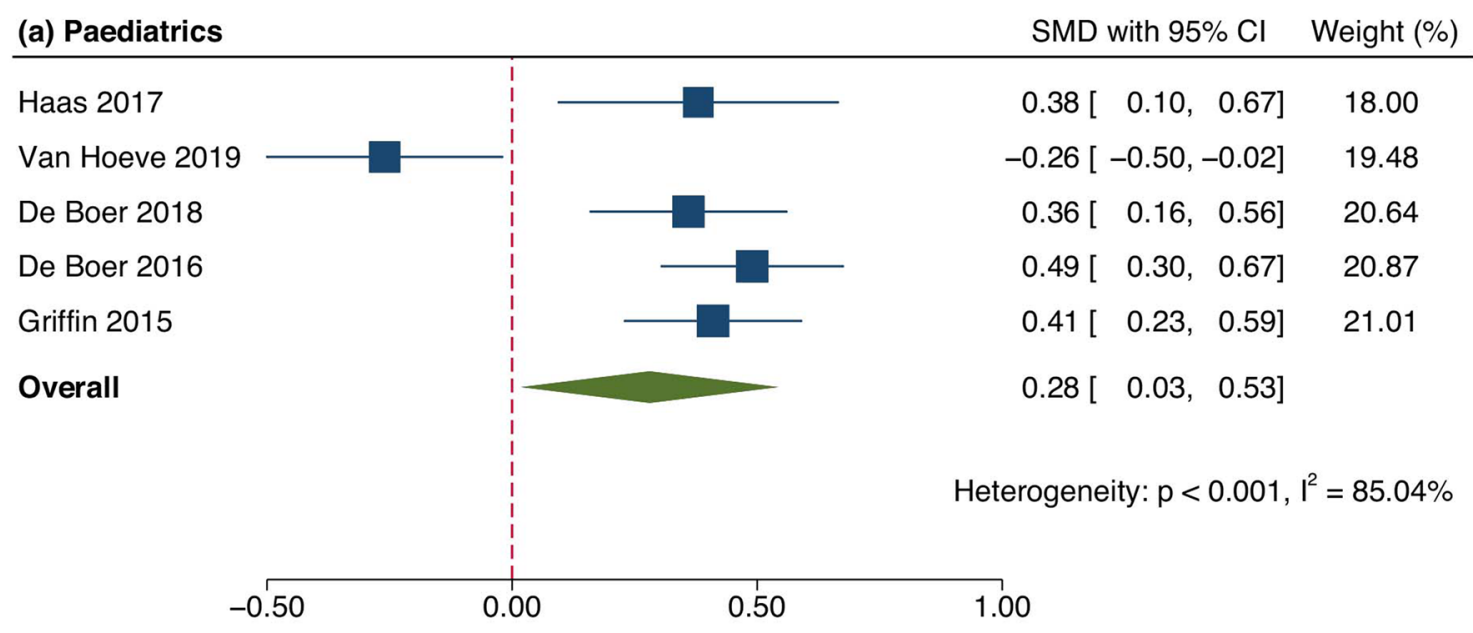

Random-effects REML model

(b) Adult patients

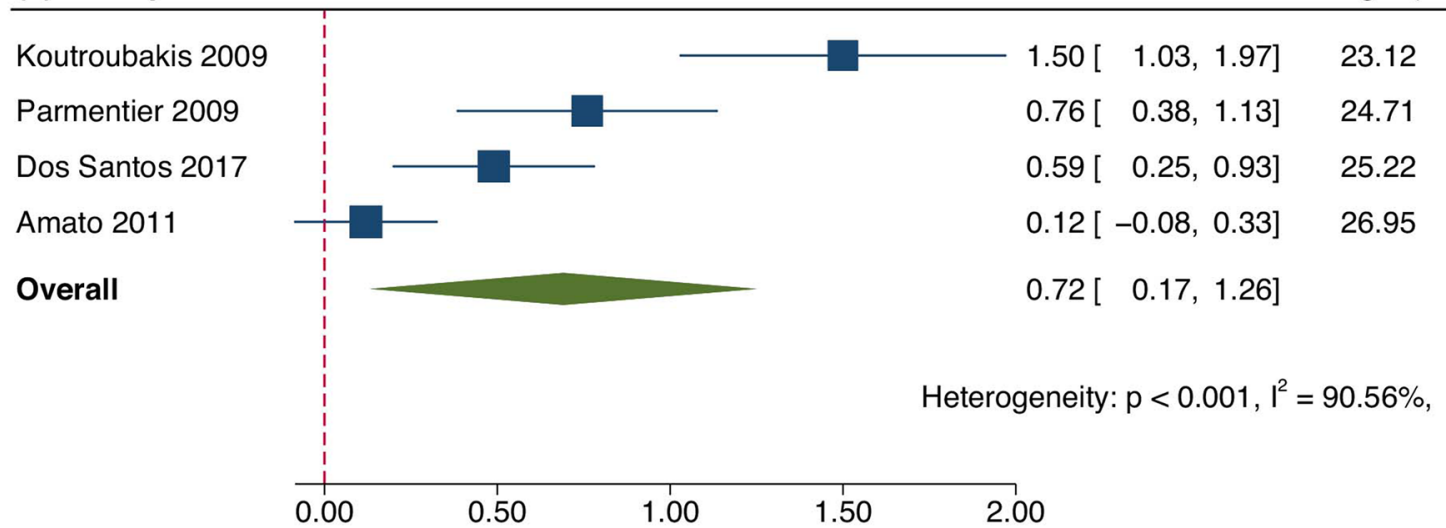

Random-effects REML model

Fig. 3 Forest plot showing the change in body mass index (BMI) between baseline and after treatment commencement with a tumour necrosis factor (TNF)- $\alpha$ inhibitor in $\mathbf{a}$ paediatric and $\mathbf{b}$ adult patients. Standardized mean difference (SMD) estimates were based on

role in body changes by ameliorating the disease status [24, 30, 32, 34].

The adult patients in our analysis were of normal weight (BMI ranged from $21.9-24.4 \mathrm{~kg} / \mathrm{m}^{2}$ ), except for three studies in which $<30 \%$ of the cohort were underweight [32, 34, 38]; therefore, the increase in body parameters from the baseline raises concerns over cardiometabolic diseases and the inferior response of anti-TNF $\alpha$ treatments in patients with IBD [43]. Conversely, paediatric patients were underweight (BMI $z$ scores ranged from -1 to -0.1 ), suggesting that the beneficial impact of the increase in these parameters was limited to the paediatric clinical setting.

At the end of follow-up (range 6-36 months), all included studies reported significant increases in both weight and height in children. It would have been interesting to
Cohen's $d$ with corresponding 95\% confidence intervals (CIs) and were considered small $(d=0.2)$, medium $(d=0.5)$, and large $(d \geq 0.8)$ as per Cohen's classification scheme [20]. A $P$ value $<0.05$ was considered statistically significant

understand whether the weight and height gain was only anti-TNF $\alpha$ dependent or the normal growth of children over time. Reported data suggest that patients aged $<10$ years had the most weight gain; this may reflect the faster growth velocity seen in early puberty and/or a greater impact of anti-TNF $\alpha$ agents in this population. Additional studies with a larger cohort may help clarify these issues.

Although the observed increase in weight and BMI during anti-TNF $\alpha$ treatment can probably be attributed to the decline in intensity of the inflammatory response and improved nutrient absorption and utilization, an intrinsic anti-TNF $\alpha$ therapy effect cannot be ruled out. Anti-TNF $\alpha$ therapy itself may increase abdominal fat tissue in patients with IBD, likely through blockade of the TNF $\alpha$-induced lipolytic effect, a mechanism that may contribute to the 
weight and BMI gain we detected. Moreover, as an activator of nuclear factor (NF)- $\mathrm{KB}, \mathrm{TNF} \alpha$ has a remarkable effect on metabolic pathways. As a consequence, anti-TNF $\alpha$ therapy may prevent the activation of NF-кB [47], influencing both nutritional status and body composition.

Skeletal muscle and adipose tissue produce cytokines and thus play an important role in the maintenance of metabolic homeostasis [48, 49]. As nutritional status assessments based on BMI and body weight do not provide sufficient information concerning body composition, we attempted to examine changes from baseline in fat and lean mass. However, only eight studies reported body composition changes, suggesting that the effect of anti-TNF $\alpha$ treatments on body composition in patients with IBD still lacks adequate attention.

We found no significant increase in fat mass (SMD $0.24 ; 95 \% \mathrm{CI}-0.19$ to $0.66 ; P=0.272$ ), likely because of the overall short period of observation (mean 6 months; range 1-6), which probably did not allow the detection of substantial changes, with highly significant heterogeneity between studies $\left(I^{2}=81.97 ; P=0.001\right)$. Although not all studies reached statistical significance, findings from data not included in the meta-analysis showed an overall increase in total abdominal fat $(P=0.027)$ [38] in BFMI $\left(5.5 \pm 2.3\right.$ vs. $6.8 \pm 2.3 \mathrm{~kg} / \mathrm{m}^{2} ; P=0.00$ [42]; 4.57 vs. $4.76 \mathrm{~kg} /$ $\left.\mathrm{m}^{2} ; P=0.120\right)$ and in visceral fat area $\left(95.65\right.$ vs. $85.00 \mathrm{~cm}^{2}$; $P=0.730)$ [24].

While some results in terms of the effects of anti-TNF $\alpha$ therapy on fat mass were partially conflicting, data on changes in lean mass in paediatric studies $[24,26,27,31$, $35,42]$ consistently showed a significant increase after
anti-TNF $\alpha$ therapy. Investigating these studies further, all but one reported a significant increase in LBM values from baseline, as confirmed by skeletal mass $(P=0.003)$, FFMI $(P<0.00)$, LMI, muscle area $z$ scores $(P<0.001)$, and leg lean mass score $(P=0.001)$ in observation periods ranging from 3 to 12 months. Importantly, FFMI was significantly increased in patients on infliximab therapy compared with patients on conventional therapy in the study by Emerenziani et al. [26]. Only one study reported no significant change in LBM value, in patients with $C D$ after 6 months $(P=0.44)$, and this was likely because of the small sample size, i.e. seven patients [31].

A significant proportion of children with $\mathrm{CD}$ has growth impairment at diagnosis [50,51]. Whereas TNF $\alpha$ is known to be implicated in the suppression of the growth hormone axis and long bone growth [52-54], evidence regarding growth benefits during anti-TNF $\alpha$ therapy is still wanting [55], with no systematic data available yet. We now describe a small but statistically significant overall increase in height (SMD 0.16; 95\% CI 0.06-0.26; $P=0.002$ ) from baseline in paediatric patients with $\mathrm{CD}$ (along with an improvement in BMI and weight). All studies confirmed this substantial increase, after a treatment duration ranging from 9.3 to 18 months. The finding that growth (including height velocity) was more likely to improve in responders suggests that growth improves as a result of better disease control with anti-TNF $\alpha$ therapy $[32,37]$.

Some studies have suggested that, in different chronic conditions, PA can be considered a promising tool to assess nutritional status [56-58]; reduced PA values are indeed associated with unfavourable disease progression

\begin{tabular}{|c|c|c|c|c|}
\hline Study & & & SMD with $95 \% \mathrm{Cl}$ & Weight (\%) \\
\hline Borelli 2004 & i & 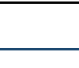 & $0.40[0.03,0.78]$ & 6.96 \\
\hline Van Hoeve 2019 & - & & $-0.02[-0.26,0.21]$ & 16.56 \\
\hline De Boer 2018 & i & & $0.20[0.01,0.40]$ & 23.30 \\
\hline De Boer 2016 & $\frac{1}{1}$ & & $0.13[-0.05,0.31]$ & 26.41 \\
\hline Griffin 2015 & 1 & & $0.20[0.02,0.38]$ & 26.77 \\
\hline Overall & $\begin{array}{l}1 \\
1 \\
1 \\
1 \\
1 \\
\\
\end{array}$ & & \multicolumn{2}{|c|}{ Heterogeneity: $p=0.34, I^{2}=11.19 \%$} \\
\hline-0.50 & 0.00 & 0.50 & 1.00 & \\
\hline
\end{tabular}

Fig. 4 Forest plot showing the change in height between baseline and after treatment commencement with a tumour necrosis factor (TNF)- $\alpha$ inhibitor in paediatric patients. Standardized mean differences (SMDs) were based on Cohen's $d$ with corresponding 95\% con- fidence intervals (CIs) and were considered small $(d=0.2)$, medium $(d=0.5)$, and large $(d \geq 0.8)$ as per Cohen's classification scheme [20]. A $P$ value $<0.05$ was considered statistically significant 


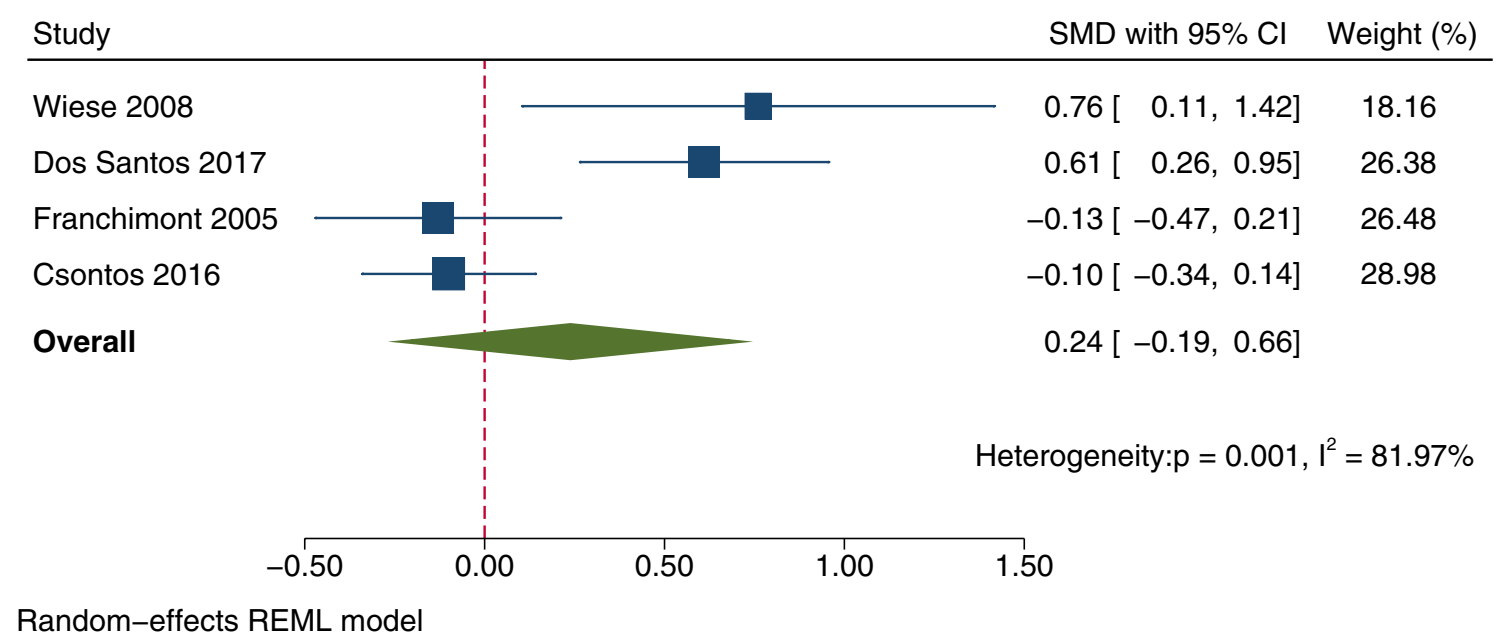

Fig. 5 Forest plot showing the change in fat mass between baseline and after treatment commencement with a tumour necrosis factor (TNF)- $\alpha$ inhibitor in adult patients. Standardized mean differences (SMDs) were based on Cohen's $d$ with corresponding 95\% confi-

and poor prognosis. More recently, PA has been assessed in paediatric patients with IBD during clinical remission [59]. Unfortunately, data on PA changes from the baseline were limited for our analysis, and findings from the only two studies reporting PA values were conflicting. Emerenziani et al. [26] found a significant increase in PA (from $4.6 \pm 0.3$ to $6.2 \pm 0.4 ; P<0.05)$, along with a substantial increase in FFMI, whereas PA remained unchanged (6.2 vs. 6.8; $P=0.94)$ in the study by Santos et al. [42] after 24 weeks of infliximab therapy. The lack of substantial improvement may be because PA decreases when fat mass increases and lean mass decreases; although patients gained both fat mass and lean mass, fat mass gain was more substantial.

\subsection{Limitations}

The main limitation of this study was that we could only include 13 of the 23 identified studies in the meta-analysis as the remaining studies did not report the required data. The absence of published randomised controlled trials on this issue forced us to include only observational studies. The limited data on potential covariates such as disease duration, disease severity, other medications, smoking, physical activity, and dietary changes prevented us conducting metaregressions to explore in more detail the effects of TNF $\alpha$ inhibitors on body changes. Moreover, the vast majority of patients included in the study (90.2\%) had CD, and only a few patients had UC. This could be an additional bias for the interpretation of the results. CD is more often associated with weight loss and growth impairment than UC, so it would be interesting to understand whether having a higher dence intervals (CIs) and were considered small $(d=0.2)$, medium $(d=0.5)$, and large $(d \geq 0.8)$ as per Cohen's classification scheme [20]. A $P$ value $<0.05$ was considered statistically significant

proportion of patients with UC would have elicited the same results.

\section{Conclusion}

Our analysis revealed an increase in the main anthropometric parameters (body weight, BMI, and height) among patients with IBD treated with TNF $\alpha$ inhibitors. These increases were also greater with longer follow-up and in responders compared with non-responders. The potential effect of TNF $\alpha$ inhibitors on anthropometric measures could be a consideration in the care of overweight and obese adults with IBD given the concerns that weight gain may be a risk factor for developing metabolic disorders and increase the likelihood of anti-TNF $\alpha$ therapy failure. In contrast, IBD was associated with impaired weight gain in children, in whom anti-TNF $\alpha$ agents could exert positive improvements in weight and linear growth. Further prospective studies are warranted to provide stronger evidence for the role of biological therapy on body changes, especially on fat and lean mass in patients with IBD.

Acknowledgements F. Mazhar is enrolled in the $\mathrm{PhD}$ in Experimental and Clinical Pharmacological Sciences, University of Milano, which supports his fellowship.

\section{Declarations}

Conflicts of Interest Faizan Mazhar, Vera Battini, Marco Pozzi, Elena Invernizzi, Giulia Mosini, Michele Gringeri, Annalisa Capuano, Cristina Scavone, Sonia Radice, Emilio Clementi, and Carla Carnovale 
have no conflicts of interest that are directly relevant to the content of this article.

Consent Not applicable.

Ethical Approval Not applicable.

Funding Open access funding provided by Università degli Studi di Milano within the CRUI-CARE Agreement. This work was supported by the Regional Center of Pharmacovigilance of Lombardy (to EC), the Italian Medicines Agency, Agenzia Italiana del Farmaco (AIFA, to EC) and by the Italian Ministry of Health (Ricerca Corrente 20192020, to MP and MN; and Progetto Finalizzata RF-2016-02363761 to EC and AC) which are gratefully acknowledged. The funding public institutions had no role in any part of the work.

Availability of Data and Material Most of the data generated or analysed during this study are included in this published article and its supplementary information files. Other datasets associated with the current study are available from the corresponding author on reasonable request.

Author Contributions FM conceptualised and designed the study, interpreted the data, drafted the manuscript, and revised and approved the final manuscript as submitted. V. Battini participated in the conceptualisation and design of the study, carried out the initial analysis, revised the manuscript, and approved the final manuscript as submitted. MP, EI, GM, MG, AC, CS, and SR participated in the conceptualisation and design of the study, analysis and interpretation of the data, revised the article, and approved the final article as submitted. E Clementi participated in the conceptualisation and design of the study, participated in the analysis and interpretation of the data, coordinated and supervised data collection, critically reviewed the manuscript and approved the final manuscript as submitted. CC conceptualised and designed the study, interpreted the data, coordinated and supervised data collection, critically reviewed the manuscript, and approved the final manuscript as submitted.

Open Access This article is licensed under a Creative Commons Attribution-NonCommercial 4.0 International License, which permits any non-commercial use, sharing, adaptation, distribution and reproduction in any medium or format, as long as you give appropriate credit to the original author(s) and the source, provide a link to the Creative Commons licence, and indicate if changes were made. The images or other third party material in this article are included in the article's Creative Commons licence, unless indicated otherwise in a credit line to the material. If material is not included in the article's Creative Commons licence and your intended use is not permitted by statutory regulation or exceeds the permitted use, you will need to obtain permission directly from the copyright holder. To view a copy of this licence, visit http://creativecommons.org/licenses/by-nc/4.0/.

\section{References}

1. Gisondi P, Cotena C, Tessari G, Girolomoni G. Anti-tumour necrosis factor-alpha therapy increases body weight in patients with chronic plaque psoriasis: a retrospective cohort study. J Eur Acad Dermatol Venereol. 2008;22(3):341-4. https://doi.org/10.1 111/j.1468-3083.2007.02429.x.

2. Sfriso P, Caso F, Filardo GS, Botsios C, Costa L, Scarpa R, et al. Impact of 24 months of anti-TNF therapy versus methotrexate on body weight in patients with rheumatoid arthritis: a prospective observational study. Clin Rheumatol. 2016;35(6):1615-8. https:// doi.org/10.1007/s10067-016-3244-7.

3. Beutler B, Greenwald D, Hulmes JD, Chang M, Pan YC, Mathison $\mathrm{J}$, et al. Identity of tumour necrosis factor and the macrophagesecreted factor cachectin. Nature. 1985;316(6028):552-4. https:// doi.org/10.1038/316552a0.

4. Plata-Salaman CR. Cytokines and Feeding. News Physiol Sci. 1998;13(6):298-304. https://doi.org/10.1152/physiologyonlin e.1998.13.6.298.

5. Chen X, Xun K, Chen L, Wang Y. TNF- $\alpha$, a potent lipid metabolism regulator. Cell Biochem Funct. 2009;27(7):407-16. https:// doi.org/10.1002/cbf.1596.

6. Florin V, Cottencin AC, Delaporte E, Staumont-Salle D. Body weight increment in patients treated with infliximab for plaque psoriasis. J Eur Acad Dermatol Venereol. 2013;27(2):e186-90. https://doi.org/10.1111/j.1468-3083.2012.04571.x.

7. Eder P, Adler M, Dobrowolska A, Kamhieh-Milz J, Witowski J. The Role of Adipose Tissue in the Pathogenesis and Therapeutic Outcomes of Inflammatory Bowel Disease. Cells. 2019;8(6):628. https://doi.org/10.3390/cells8060628.

8. Haas L, Chevalier R, Major BT, Enders F, Kumar S, Tung J. Biologic Agents Are Associated with Excessive Weight Gain in Children with Inflammatory Bowel Disease. Dig Dis Sci. 2017;62(11):3110-6. https://doi.org/10.1007/s10620-017-4745-1.

9. Singh S, Dulai PS, Zarrinpar A, Ramamoorthy S, Sandborn WJ. Obesity in IBD: epidemiology, pathogenesis, disease course and treatment outcomes. Nat Rev Gastroenterol Hepatol. 2017;14(2):110-21. https://doi.org/10.1038/nrgastro.2016.181.

10. Harper JW, Zisman TL. Interaction of obesity and inflammatory bowel disease. World J Gastroenterol. 2016;22(35):7868-81. https ://doi.org/10.3748/wjg.v22.i35.7868.

11. Long MD, Crandall WV, Leibowitz IH, Duffy L, del Rosario F, Kim SC, et al. Prevalence and epidemiology of overweight and obesity in children with inflammatory bowel disease. Inflamm Bowel Dis. 2011;17(10):2162-8. https://doi.org/10.1002/ ibd.21585.

12. Moran GW, Dubeau MF, Kaplan GG, Panaccione R, Ghosh S. The increasing weight of Crohn's disease subjects in clinical trials: a hypothesis-generatings time-trend analysis. Inflamm Bowel Dis. 2013;19(13):2949-56. https://doi.org/10.1097/MIB.0b013e3182 9936a4.

13. Nic Suibhne T, Raftery TC, McMahon O, Walsh C, O’Morain C, O'Sullivan M. High prevalence of overweight and obesity in adults with Crohn's disease: associations with disease and lifestyle factors. J Crohns Colitis. 2013;7(7):e241-8. https://doi. org/10.1016/j.crohns.2012.09.009.

14. Mostafa NM, Nader AM, Noertersheuser P, Okun M, Awni WM. Impact of immunogenicity on pharmacokinetics, efficacy and safety of adalimumab in adult patients with moderate to severe chronic plaque psoriasis. J Eur Acad Dermatol Venereol. 2017;31(3):490-7. https://doi.org/10.1111/jdv.13884.

15. Passot C, Mulleman D, Bejan-Angoulvant T, Aubourg A, Willot $\mathrm{S}$, Lecomte $\mathrm{T}$, et al. The underlying inflammatory chronic disease influences infliximab pharmacokinetics. MAbs. 2016;8(7):140716. https://doi.org/10.1080/19420862.2016.1216741.

16. Wade JR, Parker G, Kosutic G, Feagen BG, Sandborn WJ, Laveille $\mathrm{C}$, et al. Population pharmacokinetic analysis of certolizumab pegol in patients with Crohn's disease. J Clin Pharmacol. 2015;55(8):866-74. https://doi.org/10.1002/jcph.491.

17. Moher D, Liberati A, Tetzlaff J, Altman DG, Group P. Preferred reporting items for systematic reviews and meta-analyses: the PRISMA statement. Ann Intern Med. 2009;151(4):264-9. https ://doi.org/10.7326/0003-4819-151-4-200908180-00135 (W64).

18. Peterson J, Welch V, Losos M, Tugwell P. The Newcastle-Ottawa scale (NOS) for assessing the quality of nonrandomised studies in meta-analyses. Ottawa: Ottawa Hospital Research Institute; 2011. 
19. Rosenthal R. Meta-analytic procedures for social science Research Sage Publications: Beverly Hills, 1984, 148 pp. Educ Res. 1986;15(8):18-20.

20. Cohen J. A power primer. Psychol Bull. 1992;112(1):155-9. https ://doi.org/10.1037//0033-2909.112.1.155.

21. Franchimont D, Roland S, Gustot T, Quertinmont E, Toubouti Y, Gervy MC, et al. Impact of infliximab on serum leptin levels in patients with Crohn's disease. J Clin Endocrinol Metab. 2005;90(6):3510-6. https://doi.org/10.1210/jc.2004-1222.

22. Adams DW, Gurwara S, Silver HJ, Horst SN, Beaulieu DB, Schwartz DA, et al. Sarcopenia is common in overweight patients with inflammatory bowel disease and may predict need for surgery. Inflamm Bowel Dis. 2017;23(7):1182-6. https://doi. org/10.1097/MIB.0000000000001128.

23. Amato L, Cappello M, Bravata I, Randazzo C, Almasio PL, Craxi A. Serum lipid alterations in patients with inflammatory bowel disease treated with TNF alpha antagonists. Dig Liver Dis. 2011;43:S221-S. https://doi.org/10.1016/s1590-8658(11)60449-0.

24. Csontos AA, Molnar A, Piri Z, Katona B, Dako S, Palfi E, et al. The effect of anti-TNFalpha induction therapy on the nutritional status and dietary intake in inflammatory bowel disease. J Gastrointestin Liver Dis. 2016;25(1):49-56. https://doi.org/10.15403 /jgld.2014.1121.251.tnf.

25. DeBoer MD, Thayu M, Griffin LM, Baldassano RN, Denson LA, Zemel BS, et al. Increases in sex hormones during anti-tumor necrosis factor alpha therapy in adolescents with Crohn's disease. J Pediatr. 2016;171(146-52):e1-2. https://doi.org/10.1016/j.jpeds .2016.01.003.

26. Emerenziani S, Biancone L, Guarino MPL, Balestrieri P, Stasi E, Ribolsi M, et al. Nutritional status and bioelectrical phase angle assessment in adult Crohn disease patients receiving antiTNFalpha therapy. Dig Liver Dis. 2017;49(5):495-9. https://doi. org/10.1016/j.dld.2016.12.026.

27. Griffin LM, Thayu M, Baldassano RN, DeBoer MD, Zemel BS, Denburg MR, et al. Improvements in bone density and structure during anti-TNF-alpha therapy in pediatric Crohn's disease. J Clin Endocrinol Metab. 2015;100(7):2630-9. https://doi.org/10.1210/ jc.2014-4152.

28. Kierkus J, Dadalski M, Szymanska S, Szymanska E, Wegner A, Gorczewska M, et al. Maintenance therapy with infliximab for paediatric Crohn's disease: impact on clinical remission and mucosal healing in Polish paediatric patients with severe Crohn's disease. Przeglad Gastroenterol. 2012;7(1):26-30. https://doi. org/10.5114/pg.2012.27219.

29. Koutroubakis IE, Oustamanolakis P, Malliaraki N, Karmiris K, Chalkiadakis I, Ganotakis E, et al. Effects of tumor necrosis factor alpha inhibition with infliximab on lipid levels and insulin resistance in patients with inflammatory bowel disease. Eur J Gastroenterol Hepatol. 2009;21(3):283-8. https://doi.org/10.1097/ MEG.0b013e328325d42b.

30. Miranda-Bautista J, de Gracia-Fernandez C, Lopez Ibanez M, Barrientos M, Gallo-Molto A, Gonzalez Arias M, et al. Lipid profile in inflammatory bowel disease patients on anti-TNFalpha therapy. Dig Dis Sci. 2015;60(7):2130-5. https://doi.org/10.1007/ s10620-015-3577-0.

31. Wiese D, Lashner B, Seidner D. Measurement of nutrition status in Crohn's disease patients receiving infliximab therapy. Nutr Clin Pract. 2008;23(5):551-6. https://doi.org/10.1177/0884533608 323421.

32. Assa A, Hartman C, Weiss B, Broide E, Rosenbach Y, Zevit N, et al. Long-term outcome of tumor necrosis factor alpha antagonist's treatment in pediatric Crohn's disease. J Crohns Colitis. 2013;7(5):369-76. https://doi.org/10.1016/j.crohns.2012.03.006.

33. Borrelli O, Bascietto C, Viola F, de Mesquita BM, Barbato M, Mancini $\mathrm{V}$, et al. Infliximab heals intestinal inflammatory lesions and restores growth in children with Crohn's disease. Dig Liver Dis. 2004;36(5):342-7. https://doi.org/10.1016/j.dld.2003.12.014.

34. Branquinho DPF, Mendes S, Ferreira M, Portela F, Sofia C, et al. Body mass index variation in INFLIXIMAB-treated IBD patients: United European Gastroenterology Week Vienna, Austria, October 18-22. United Eur Gastroenterol J. 2014;2(1S):A132-605.

35. DeBoer MD, Lee AM, Herbert K, Long J, Thayu M, Griffin LM, et al. Increases in IGF-1 after anti-TNF-alpha therapy are associated with bone and muscle accrual in pediatric crohn disease. J Clin Endocrinol Metab. 2018;103(3):936-45. https://doi. org/10.1210/jc.2017-01916.

36. Gouldthorpe O, Catto-Smith AG, Alex G, Simpson D. Loss of response to long-term infliximab therapy in children with Crohn's disease. Pharmaceuticals (Basel). 2013;6(10):1322-34. https:// doi.org/10.3390/ph6101322.

37. Malik S, Ahmed SF, Wilson ML, Shah N, Loganathan S, Naik S, et al. The effects of anti-TNF-alpha treatment with adalimumab on growth in children with Crohn's disease (CD). J Crohns Colitis. 2012;6(3):337-44. https://doi.org/10.1016/j.crohns.2011.09.004.

38. Parmentier-Decrucq E, Duhamel A, Ernst O, Fermont C, Louvet $A$, Vernier-Massouille G, et al. Effects of infliximab therapy on abdominal fat and metabolic profile in patients with Crohn's disease. Inflamm Bowel Dis. 2009;15(10):1476-84. https://doi. org/10.1002/ibd.20931.

39. Vadan R, Gheorghe LS, Constantinescu A, Gheorghe C. The prevalence of malnutrition and the evolution of nutritional status in patients with moderate to severe forms of Crohn's disease treated with Infliximab. Clin Nutr. 2011;30(1):86-91. https://doi. org/10.1016/j.clnu.2010.07.019.

40. van Hoeve K, Dreesen E, Hoffman I, Van Assche G, Ferrante M, Gils A, et al. Efficacy, Pharmacokinetics, and Immunogenicity is Not Affected by Switching From Infliximab Originator to a Biosimilar in Pediatric Patients With Inflammatory Bowel Disease. Ther Drug Monit. 2019;41(3):317-24. https://doi.org/10.1097/ FTD.0000000000000601.

41. Kierkus J, Dadalski M, Szymanska E, Oracz G, Wegner A, Gorczewska M, et al. The impact of infliximab induction therapy on mucosal healing and clinical remission in Polish pediatric patients with moderate-to-severe Crohn's disease. Eur J Gastroenterol Hepatol. 2012;24(5):495-500. https://doi.org/10.1097/ MEG.0b013e32835159f2.

42. Santos JCD, Malaguti C, Lucca FA, Cabalzar AL, Ribeiro T, Gaburri PD et al. Impact of biological therapy on body composition of patients with Chron's disease. Rev Assoc Med Bras (1992). 2017;63(5):407-13. https://doi.org/10.1590/1806-9282.63.05.407.

43. Dai ZH, Xu XT, Ran ZH. Associations between obesity and the effectiveness of anti-tumor necrosis factor-alpha agents in inflammatory bowel disease patients: a literature review and meta-analysis. Ann Pharmacother. 2020. https://doi.org/10.1177/1060028019 900660.

44. Engvall IL, Tengstrand B, Brismar K, Hafstrom I. Infliximab therapy increases body fat mass in early rheumatoid arthritis independently of changes in disease activity and levels of leptin and adiponectin: a randomised study over 21 months. Arthritis Res Ther. 2010;12(5):R197. https://doi.org/10.1186/ar3169.

45. Renzo LD, Saraceno R, Schipani C, Rizzo M, Bianchi A, Noce A, et al. Prospective assessment of body weight and body composition changes in patients with psoriasis receiving anti-TNF-alpha treatment. Dermatol Ther. 2011;24(4):446-51. https://doi.org/10 $.1111 / j .1529-8019.2011 .01439 . x$.

46. Serelis J, Kontogianni MD, Katsiougiannis S, Bletsa M, Tektonidou MG, Skopouli FN. Effect of anti-TNF treatment on body composition and serum adiponectin levels of women with rheumatoid arthritis. Clin Rheumatol. 2008;27(6):795-7. https://doi. org/10.1007/s10067-008-0855-7. 
47. Nikolaus S, Raedler A, Kuhbacker T, Sfikas N, Folsch UR, Schreiber S. Mechanisms in failure of infliximab for Crohn's disease. Lancet. 2000;356(9240):1475-9. https://doi.org/10.1016/ s0140-6736(00)02871-3.

48. Juge-Aubry CE, Henrichot E, Meier CA. Adipose tissue: a regulator of inflammation. Best Pract Res Clin Endocrinol Metab. 2005;19(4):547-66. https://doi.org/10.1016/j.beem.2005.07.009.

49. Pratesi A, Tarantini F, Di Bari M. Skeletal muscle: an endocrine organ. Clin Cases Miner Bone Metab. 2013;10(1):11-4. https:// doi.org/10.11138/ccmbm/2013.10.1.011.

50. Motil KJ, Grand RJ, Davis-Kraft L, Ferlic LL, Smith EO. Growth failure in children with inflammatory bowel disease: a prospective study. Gastroenterology. 1993;105(3):681-91. https://doi. org/10.1016/0016-5085(93)90883-e.

51. Sawczenko A, Sandhu BK. Presenting features of inflammatory bowel disease in Great Britain and Ireland. Arch Dis Child. 2003;88(11):995-1000. https://doi.org/10.1136/adc.88.11.995.

52. Wong SC, Smyth A, McNeill E, Galloway PJ, Hassan K, McGrogan P, et al. The growth hormone insulin-like growth factor 1 axis in children and adolescents with inflammatory bowel disease and growth retardation. Clin Endocrinol (Oxf). 2010;73(2):220-8. https://doi.org/10.1111/j.1365-2265.2010.03799.x.

53. MacRae VE, Farquharson C, Ahmed SF. The restricted potential for recovery of growth plate chondrogenesis and longitudinal bone growth following exposure to pro-inflammatory cytokines. J Endocrinol. 2006;189(2):319-28. https://doi.org/10.1677/ joe.1.06609.

54. Pfefferkorn M, Burke G, Griffiths A, Markowitz J, Rosh J, Mack $\mathrm{D}$, et al. Growth abnormalities persist in newly diagnosed children with crohn disease despite current treatment paradigms. J Pediatr Gastroenterol Nutr. 2009;48(2):168-74. https://doi.org/10.1097/ MPG.0b013e318175ca7f.

55. Walters TD, Gilman AR, Griffiths AM. Linear growth improves during infliximab therapy in children with chronically active severe Crohn's disease. Inflamm Bowel Dis. 2007;13(4):424-30. https://doi.org/10.1002/ibd.20069.

56. Kyle UG, Bosaeus I, De Lorenzo AD, Deurenberg P, Elia M, Manuel Gomez J, et al. Bioelectrical impedance analysis-part II: utilization in clinical practice. Clin Nutr. 2004;23(6):1430-53. https://doi.org/10.1016/j.clnu.2004.09.012.

57. Nagano M, Suita S, Yamanouchi T. The validity of bioelectrical impedance phase angle for nutritional assessment in children. J Pediatr Surg. 2000;35(7):1035-9. https://doi.org/10.1053/ jpsu.2000.7766.

58. Barbosa-Silva MC, Barros AJ, Wang J, Heymsfield SB, Pierson RN Jr. Bioelectrical impedance analysis: population reference values for phase angle by age and sex. Am J Clin Nutr. 2005;82(1):49-52. https://doi.org/10.1093/ajcn.82.1.49.

59. Werkstetter KJ, Ullrich J, Schatz SB, Prell C, Koletzko B, Koletzko S. Lean body mass, physical activity and quality of life in paediatric patients with inflammatory bowel disease and in healthy controls. J Crohns Colitis. 2012;6(6):665-73. https://doi. org/10.1016/j.crohns.2011.11.017.

\section{Affiliations}

\section{Faizan Mazhar ${ }^{1}$ - Vera Battini ${ }^{1}$ - Marco Pozzi ${ }^{2}$ - Elena Invernizzi ${ }^{1}$. Giulia Mosini ${ }^{1}$ - Michele Gringeri ${ }^{1}$. Annalisa Capuano $^{3} \cdot$ Cristina Scavone $^{3} \cdot$ Sonia Radice ${ }^{1} \cdot$ Emilio Clementi $^{1,2} \cdot$ Carla Carnovale $^{1}$}

1 Unit of Clinical Pharmacology, Department of Biomedical and Clinical Sciences L. Sacco, "Luigi Sacco" University Hospital, Università di Milano, 20157 Milan, Italy

2 Scientific Institute, IRCCS E. Medea, Bosisio Parini, LC, Italy

3 Section of Pharmacology "L. Donatelli", Department of Experimental Medicine, Campania Regional Centre for Pharmacovigilance and Pharmacoepidemiology,
University of Campania "Luigi Vanvitelli”, Via

Costantinopoli 16, 80138 Naples, Italy 